NBER WORKING PAPER SERIES

\title{
ANTITRUST AND INNOVATION: WELCOMING AND PROTECTING DISRUPTION
}

\author{
Giulio Federico \\ Fiona Scott Morton \\ Carl Shapiro \\ Working Paper 26005 \\ http://www.nber.org/papers/w26005 \\ NATIONAL BUREAU OF ECONOMIC RESEARCH \\ 1050 Massachusetts Avenue \\ Cambridge, MA 02138 \\ June 2019
}

Federico is a Head of Unit at the Chief Economist Team of the Directorate-General for Competition, European Commission. Scott Morton is the Theodore Nierenberg Professor of Economics at the Yale University School of Management. Shapiro is a Professor at the Haas School of Business at the University of California at Berkeley. The views expressed in the text are the private views of the authors and may not, under any circumstances, be interpreted as stating an official position of the European Commission. We thank Mike Andrews, Richard Gilbert, Gregor Langus, Angel Lopez and Scott Stern for comments on a draft of the paper. The views expressed herein are those of the authors and do not necessarily reflect the views of the National Bureau of Economic Research.

At least one co-author has disclosed a financial relationship of potential relevance for this research. Further information is available online at http://www.nber.org/papers/w26005.ack

NBER working papers are circulated for discussion and comment purposes. They have not been peer-reviewed or been subject to the review by the NBER Board of Directors that accompanies official NBER publications.

(C) 2019 by Giulio Federico, Fiona Scott Morton, and Carl Shapiro. All rights reserved. Short sections of text, not to exceed two paragraphs, may be quoted without explicit permission provided that full credit, including $\odot$ notice, is given to the source. 
Antitrust and Innovation: Welcoming and Protecting Disruption

Giulio Federico, Fiona Scott Morton, and Carl Shapiro

NBER Working Paper No. 26005

June 2019

JEL No. L1,L10,L12,L13,L4,O3

\begin{abstract}
$\underline{\text { ABSTRACT }}$
The goal of antitrust policy is to protect and promote a vigorous competitive process. Effective rivalry spurs firms to introduce new and innovative products, as they seek to capture profitable sales from their competitors and to protect their existing sales from future challengers. In this fundamental way, competition promotes innovation. We apply this basic insight to the antitrust treatment of horizontal mergers and of exclusionary conduct by dominant firms. A merger between rivals internalizes business-stealing effects arising from their parallel innovation efforts and thus tends to depress innovation incentives. Merger-specific synergies, such as the internalization of involuntary spillovers or an increase in the productivity of R\&D, may offset the adverse effect of a merger on innovation. We describe the possible effects of a merger on innovation by developing a taxonomy of cases, with reference to recent U.S. and E.U. examples. A dominant firm may engage in exclusionary conduct to eliminate the threat from disruptive firms. This suppresses innovation by foreclosing disruptive rivals and by reducing the pressure to innovative on the incumbent. We apply this broad principle to possible exclusionary strategies by dominant firms.

Giulio Federico

European Commission

Giulio.FEDERICO@ec.europa.eu

Fiona Scott Morton

Yale School of Management Box

208200

New Haven, CT 06520-8200 and

NBER

fiona.scottmorton@yale.edu

Carl Shapiro

Haas School of Business

University of California, Berkeley

Berkeley, CA 94720

and NBER

cshapiro@berkeley.edu
\end{abstract}




\section{Antitrust and Innovation: Welcoming and Protecting Disruption* \\ Giulio Federico, Fiona Scott Morton and Carl Shapiro ${ }^{\dagger}$ \\ Table of Contents}

1. Introduction ..................................................................................................................1

2. Horizontal Mergers and Innovation: Key Economic Concepts ............................2

2.1 The Competitive Process and "Business Stealing" ............................................................ 3

2.2 Harmful Effects on Innovation: Internalization of Business Stealing .................................. 5

2.3 Beneficial Effects on Innovation: Innovation Synergies ..................................................... 7

2.4 The Misleading Economic Literature on “Competition and Innovation” ............................. 10

3. Horizontal Mergers and Innovation: Applications and Case Studies ...............11

3.1 Product-to-Pipeline and Pipeline-to-Pipeline Overlaps ........................................................ 12

3.2 Overlaps in Capabilities.............................................................................................................. 18

3.3 Acquisitions of Potential Competitors by Dominant Firms ............................................... 21

4. Exclusionary Conduct by Dominant Firms in Innovative Industries.................24

4.1 Establishing an Appropriate Counterfactual............................................................................... 24

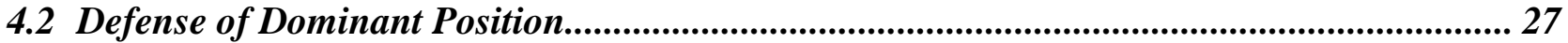

4.3 Extension of Dominant Position ................................................................................................ 29

Appendix A: The Interaction Between Unilateral Price and Innovation Effects ..37

Appendix B: Selected Antitrust Cases Involving Innovation .......................................40

* Prepared for the NBER, Innovation Policy and the Economy, 2019. The latest version of this paper is available at http://faculty.haas.berkeley.edu/shapiro/disruption.pdf.

${ }^{\dagger}$ Federico is a Head of Unit at the Chief Economist Team of the Directorate-General for Competition, European Commission. Scott Morton is the Theodore Nierenberg Professor of Economics at the Yale University School of Management. Shapiro is a Professor at the Haas School of Business at the University of California at Berkeley. The views expressed in the text are the private views of the authors and may not, under any circumstances, be interpreted as stating an official position of the European Commission. We thank Mike Andrews, Richard Gilbert, Gregor Langus, Angel Lopez and Scott Stern for comments on a draft of the paper. 


\section{Introduction}

We write in praise of market disrupters - firms that shake up the status quo, threaten incumbent firms, and sometimes transform entire industries. Through this process, which Schumpeter famously called "creative destruction," disruptive firms promote economic growth and bring the benefits of new technologies and new business practices and business models to consumers.

We focus on the impact of antitrust policy - known globally as competition policy - on innovation. ${ }^{1}$ Competition policy seeks to protect and promote a vigorous competitive process by which new ideas are transformed into realized consumer benefits. In this fundamental way, competition spurs innovation. The productivity and growth literatures teach us that innovation is the primary driver of rising standards of living over time, so promoting innovation through effective competition policy is likely to be very consequential for economic growth and welfare.

A significant amount of innovation is driven by disruptive firms. ${ }^{2}$ Disruptive firms do not use the same technology or business model as incumbents. They offer consumers a distinct value proposition, not simply lower prices. By making its offer to customers attractive in a new way, a disruptive firm can destroy a great deal of incumbent profit while creating a large amount of consumer surplus. The resulting churn in products and market shares, as new products enter and old ones exit, and as newer business methods and business models supplant older ones, represents a healthy competitive process. If that competitive process is slowed or biased by mergers or by exclusionary conduct, innovation is lessened and consumers are harmed. This same competitive process promotes the development and diffusion of best practices, including what might be termed reductions in X-inefficiency. The trade and productivity literatures both convincingly demonstrate that firms vary significantly in their productivity levels and that stiffer competition reallocates sales to more productive firms. The diffusion of best practices also is promoted if sales are contestable, going to the better-performing firms.

Competition policy seeks to protect the competitive process by which disruptive firms challenge the status quo. Competition policy is agnostic regarding the type of firm or the type of innovation involved. Startups that grow rapidly can certainly be disruptive. Uber and Airbnb are prominent recent examples. But large established firms can also be disruptive, especially when they attack adjacent markets. Think of Wal-Mart entering local retail markets, Microsoft Bing challenging Google in search, or Netflix producing its own video content.

In contrast, the role played by successful incumbent firms in their own core markets is deeply conflicted. On the one hand, process innovations that lower costs can be most valuable at the largest firms, and market leaders often invest substantial sums to introduce new generations of products. Examples abound: Intel developing a new generation of technology and building new fabs to manufacture microprocessors; Boeing developing a new generation of large commercial aircraft; and Verizon investing to build its 5G wireless network. Indeed, in many industries

\footnotetext{
${ }^{1}$ Competition policy works in concert with other foundational public policies for promoting innovation, including intellectual property policy, government funding for basic research, policies to develop a skilled work force, and policies to sustain a robust financial system. Our antitrust analysis takes these other policies as given.

${ }^{2}$ We use the term "disruption” broadly to encompass a wide range of activities that challenge the status quo. Gans (2016) usefully develops a much more specific notion of disruption, as viewed from the perspective of a current market leader: "when successful firms fail because they continue to make the choices that drove their success."
} 
experiencing rapid technological change, the biggest firms are also some of the most impressive innovators, as Schumpeter observed 75 years ago. This should not be surprising, given the economies of scale associated with $R \& D$, especially in industries where developing the nextgeneration product or process requires investments of hundreds of millions of dollars and/or extensive experience with the current technology. ${ }^{3}$ On the other hand, a successful incumbent firm that is profiting greatly from the status quo has a powerful incentive to preserve those profits, and this can mean slowing down or blocking disruptive threats. Successful incumbents also may find it very difficult organizationally to invest in disruptive technologies. ${ }^{4}$ Competition valuably increases the diversity of approaches taken to the development of new technology.

We stress in this paper that innovation is best promoted when market leaders are allowed to exploit their competitive advantages while also facing pressure to perform coming from both conventional rivals and from disruptive entrants. These labels depend on context: the same firm can be a market leader in one area and a disruptive upstart in another. Market leaders may face competitive pressures to innovate coming from (a) other large firms in the same market, (b) other large firms in adjacent spaces, or (c) smaller, pesky disruptive firms. Casual empiricism indicates that all of these sources of competition are important in different settings. No doubt they are all worthy of protection using competition policy.

The central theme animating our analysis is that a market leader is best motivated to innovate if it fears losing its leadership position to a disruptive rival. ${ }^{5}$ Even a dominant incumbent will feel pressure to innovate if the bulk of tomorrow's sales will be won by the firm that is most innovative, be that the incumbent or a disruptive challenger, and if other firms are in a position to leapfrog the current incumbent. Once one properly understands the dynamic nature of the competitive process, it becomes clear that greater rivalry - meaning greater contestability of tomorrow's sales - leads to more innovation. ${ }^{6}$ The critical role of competition policy is thus to prevent today's market leaders from using their market power to disable disruptive threats, either by acquiring would-be rivals or by using anti-competitive tactics to exclude them.

Sections 2 and 3 discusses the treatment of horizontal mergers that may harm innovation. Section 4 discusses the antitrust limits on the business conduct of dominant incumbent firms.

\section{Horizontal Mergers and Innovation: Key Economic Concepts}

This section discusses the key economic concepts used in the antitrust analysis of horizontal mergers for which there are concerns that the merger may adversely affect the pace and direction of innovation. We include in the category of "horizontal mergers" all mergers that combine actual or potential competitors. This includes mergers involving firms that do not currently

\footnotetext{
${ }^{3}$ The largest firms are often the most successful innovators precisely because innovation has allowed them to acquire a strong position in the market, so there can be reverse causality between firm size and innovation.

${ }^{4}$ This is an old but powerful idea in organizational behavior and economics. See, for example, Christensen (1997) and Bresnahan et al. (2012).

${ }^{5}$ Shapiro (2012, p. 364) captured this core idea with the “contestability” principle: "The prospect of gaining or protecting profitable sales by providing greater value to customers spurs innovation.”

${ }^{6}$ Below, we address and dismiss the contrary proposition that "more competition might lead to less innovation." This notion, which has taken root in some quarters under the banner of a purported inverse-U shaped relationship between competition and innovation, is subject to misuse in antitrust.
} 
compete but may offer competing products or services in the future based on either their current research and development efforts or their overall capabilities.

Our analysis here builds on and updates previous articles relating to mergers and innovation. See especially Katz and Shelanski (2005), Gilbert (2006), Baker (2007), and Shapiro (2012). ${ }^{7}$

We evaluate mergers using the criterion generally applied by antitrust enforcers around the world, including in the United States and the European Union: a merger is considered anticompetitive if it may substantially lessen competition. Under this legal standard, a merger is illegal if it is likely to meaningfully harm customers as a result of diminished competition. Our analysis thus focuses on the effect of a merger on the customers of the merging firms. This is the approach taken by the U.S. Horizontal Merger Guidelines. Section 6.4 of those Guidelines, “Innovation and Product Variety,” describes how the U.S. Department of Justice and the Federal Trade Commission evaluate horizontal mergers that may lessen innovation. The European Commission's Horizontal Merger Guidelines also focus on how a merger will impact customers.

\subsection{The Competitive Process and "Business Stealing"}

In a market economy, competition is best described as a dynamic process of rivalry between firms seeking to attract customers by offering them a better deal. Rivalry creates incentives for firms to offer lower prices and to introduce new and improved products, because those activities enable successful firms to win profitable business from competitors and to protect and retain their existing profitable sales. ${ }^{8}$

This dynamic competitive process between direct rivals centers on what are generally known as "business-stealing effects." Business-stealing effects arise ubiquitously, because one firm's gain in customers by offering them better value typically comes at the expense of its rivals. Businessstealing effects are widely beneficial to customers because they go hand-in-hand with the competitive actions that firms take precisely to make their market offerings more attractive to customers and thus entice them away from rival firms.

Our focus here in on innovation, so we are especially interested in the business-stealing effects that arise when one firm undertakes risky investments to develop new and improved products or production processes. For simplicity and ease of exposition, we focus on product innovation, but by and large our analysis applies equally well to process innovation.

While some innovation is driven by the prospect of serving entirely new uses, or capturing sales from highly competitive industries with small price/cost margins, many of the rewards to innovation are commonly driven by the prospect of attracting customers that would otherwise purchase other products with significant price/cost margins. This occurs, for example, when firms race to be first to the market in a new product category, or to leapfrog each other with successive product improvements.

Suppose that Firm A has already developed and launched Product A, but now Firm B is investing to develop a new Product B that will compete against Product A. In this setting, Firm B's innovative efforts exert a negative pecuniary externality on Firm A. The business-stealing

\footnotetext{
${ }^{7}$ For a recent review, see also Baker (2019, chapter 8).

${ }^{8}$ For a brief review of the historical foundations of the principle of competition as a dynamic process of rivalry, and implications for merger control, see Federico (2017) and the references therein.
} 
effect of Product B on Product A is largest if those two products are close substitutes. Importantly, the negative pecuniary externality that Firm B's introduction of Product B exerts on Firm A is larger, the higher is Firm A's pre-existing price/cost margin on Product A.

The importance of business-stealing effects for innovation incentives has long been understood. Arrow's famous replacement effect (Arrow 1962; Tirole 1988) is closely linked to innovationrelated business-stealing effects. In Arrow's model of process innovation in the market for a homogenous product, a secure product-market monopolist faces weaker (net) incentives to innovate than does a firm in a perfectly competitive pre-innovation market, because the monopolist is already earning substantial profits in the pre-innovation status quo, while the competitive firm is not. ${ }^{9}$ Business-stealing effects are also present in models of patent races under uncertainty. ${ }^{10}$ In these models, competition between rival innovators typically accelerates the timing of innovation because any given firm does not internalize the adverse businessstealing effects that its success imposes on the other firms. ${ }^{11}$ One of the robust lessons from this literature is that competition from rival innovators acts as a powerful incentive for innovation. A secure incumbent would invest less on R\&D than a threatened incumbent, because it does not need to fear losing its business to rivals. Likewise, in the literature on R\&D joint ventures, absent spillovers, cooperation between rivals leads to lower innovative efforts because it internalizes the business-stealing effects on innovation. ${ }^{12}$

An important feature of rivalry to develop new products is that firms must undertake risky investments to develop those products. Firms only make investment decisions of that type if they perceive a good enough prospect of earning sufficient profit margins on the resulting products to provide an adequate risk-adjusted rate of return on investment. Inherent in this whole enterprise is that successful products will earn sizeable operating profits, which requires sufficient volumes at a price exceeding marginal cost. These price/cost margins make business stealing both attractive to challengers and threatening to incumbents. Indeed, if the fixed costs of product development are high, and if new product development is risky, in equilibrium these margins must be quite substantial to justify the necessary development expenses. In other words, when discussing the treatment of innovation effects in merger analysis, it is important to bear in mind that we are not talking about industries in which traditional price competition drives prices down to marginal cost. Therein lies a key point: the very same industry conditions that stimulate innovation, by allowing successful innovators to earn large price/cost margins, make business stealing effects more consequential.

\footnotetext{
${ }^{9}$ In the context of merger control policy, one can think of Arrow's model as capturing the effects on innovation of a merger to monopoly among the many firms supplying a homogeneous product. That merger increases preinnovation profits to the monopoly level and hence reduces the net gain from innovation. However, Arrow's model is not suitable for studying actual mergers, because it makes two assumptions that are not normally valid in practice: (1) there is only one possible innovator, and (2) product market competition dissipates all pre-innovation rents.

${ }^{10}$ See for example Reinganum (1989).

${ }^{11}$ See Tirole (1988). Business-stealing effects are also explicitly recognized in the literature on endogenous growth. See, for example, Aghion and Howitt (1992) for a model of "creative destruction" through vertical product differentiation.

${ }^{12}$ See, for example, d’Aspremont and Jacquemin (1988) and Lopez and Vives (forthcoming).
} 


\subsection{Harmful Effects on Innovation: Internalization of Business Stealing}

How should one evaluate mergers in this type of dynamic, innovative market environment? More specifically, what basic economic lines of inquiry typically arise when one evaluates the likely effect of a proposed horizontal merger on the incentive and ability of the merged firm to compete by investing resources to develop new products?

For this purpose, it is useful first to briefly review how one evaluates the likely effect of a proposed horizontal merger on the incentive of the merged firm to compete on price. A standard and common concern is that a merger between two firms that are significant direct competitors will lead to higher prices simply by virtue of eliminating that direct competition. This analysis takes as given the competition provided by all other (non-merging) firms. Adverse competitive effects of this type are called unilateral price effects, indicating that they arise through the unilateral, profit-maximizing conduct of the merged entity. Unilateral price effects distill the effects of the changing pricing incentives that result when competing products are brought under common ownership. Concerns about unilateral price effects apply to future products as well as to existing products. Unilateral effects are distinct from coordinated effects, which involve postmerger coordination between the merged entity and its remaining rivals.

The key economic idea behind unilateral price effects is that the merger internalizes pricerelated business stealing effects between the two merging firms and thus leads to less price competition and higher prices. This inherently tends to harm customers, all else equal. To see the underlying logic, consider a merger between Firm A and Firm B. Suppose that Firm A sells Products A1 and A2 and Firm B sells Product B, all of which are imperfect substitutes for each other. Examples include brands of breakfast cereal or beer, or models of automobiles. Prior to the merger, Firm A will evaluate a possible reduction in the price of Product A1 based on its impact on the profits it earns on Products A1 and A2. After the merger, the merged entity evaluating that same price cut will also include its impact on Product B. The price cut of Product A1 will be less attractive to the merged entity to the extent that induces customers to shift their purchases from Product B to Product A1. For this reason, mergers that combine products that compete significantly against each other inherently lessen price competition and harm customers, absent some merger-specific synergies.

The magnitude of these unilateral price effects is most directly measured based on the upward pricing pressure caused by internalizing the business-stealing effects between the products sold by Firm A and those sold by Firm B. ${ }^{13}$ If those effects are large, there is a presumption that the merger will lead to higher prices, unless it creates merger-specific cost-reductions sufficient to offset these effects. ${ }^{14}$ Antitrust law reflects these basic economic idea through the structural presumption, under which a merger that significantly raises market concentration is presumed to significantly harm competition. ${ }^{15}$ That presumption can be rebutted with evidence that the

\footnotetext{
13 See O’Brien and Salop (2001) and Farrell and Shapiro (2010).

${ }^{14}$ See Werden (1996) and Farrell and Shapiro (2010).

15 See Hovenkamp and Shapiro (2018). Economic analysis indicates that unilateral price effects depend primarily on price/cost margins and the cross-elasticity of demand (diversion) between the products sold by the merging firms, but the case law has developed over a long period of time to look at market concentration. In large part this reflects historical concerns with coordinated price effects rather than unilateral price effects.
} 
merger is unlikely to enhance market power (e.g. with a showing that the merger is likely to generate sufficient synergies that would not otherwise be achieved).

Unilateral innovation effects are closely analogous to unilateral price effects, with the focus on firms' decisions to invest resources to develop new products rather than on their pricing decisions. The first step in assessing possible unilateral innovation effects is to look for innovation-related business stealing effects between the two merging firms. If these effects are significant, the next step is to look for merger-specific synergies that might offset these effects.

As an especially clear example, important in practice, suppose that Firm A sells a blockbuster pharmaceutical drug and Firm B is in the process of developing a competing drug. In this context, there is a natural and serious concern that a merger between Firms A and B will cause the merged entity to either slow down or entirely drop the development of that new drug. ${ }^{16}$ This concern is greatest if Firm A is earning large price/cost margins on its blockbuster drug (the norm) and if the bulk of the sales of Firm B's new drug would come at the expense of Firm A's drug (also common if the new drug is in the same therapeutic class as the blockbuster drug). Cunningham et al. (2019) find evidence of pharmaceutical acquisitions with exactly these characteristics: companies acquire drugs under development that threaten their own current products and then shut down those development efforts.

The central lesson here is that anti-competitive unilateral innovation effects, just like unilateral price effects, are greatest in situations where the price/cost margins on the relevant products are large and where the business-stealing effects between the two firms are substantial.

The simplest and most direct way to measure the unilateral innovation effects associated with a merger between Firm A and Firm B on Firm B's innovation incentives is to calculate the innovation diversion ratio. This ratio is defined as the expected lost profits at Firm A, caused by successful development of Product B, measured in proportion to the expected extra profits Firm $\mathrm{B}$ would achieve from that success. ${ }^{17}$ The innovation diversion ratio includes both the quantity effects and the price effects of Firm B's new product on all of Firm A's products. The higher the innovation diversion ratio, the more important are the business stealing effects, and the more likely that the merged entity will scale back or terminate the development of Product $\mathrm{B}$. The innovation diversion ratio measures the extent of the "tax" on the Product B development project that the merged entity will effectively face due to the internalization of business-stealing effects.

In practice, if Firm $\mathrm{A}$ is also undertaking risky product development efforts, the innovation diversion ratio will depend on the likelihood that Firm A's efforts bear fruit, conditional on success by Firm B. In general, all else equal, the internalization of business stealing resulting from a merger will be larger, the higher the correlation between the two firms' development projects. With high correlation, the merged firm may regard cancelling one project as eliminating "duplicative" projects, but from a competition perspective that also eliminates the prospect that the two resulting products will compete against each other. That probabilistic loss of competition predictably harms consumers.

\footnotetext{
16 The FTC has long been concerned about pharmaceutical mergers for precisely this reason, and has challenged several on this basis. Shapiro (2012) highlights the Genzyme/Novazyme merger as a stark example where the FTC failed to challenge a merger that would predictably have harmful effect on innovation. In 2011 the FTC challenged a merger to monopoly but the was unable to prevail in court. FTC v. Lundbeck, 650 F. 3d 1236 (Eight Circuit, 2011).

${ }^{17}$ See Farrell and Shapiro (2010).
} 
A single merger can cause unilateral innovation effects together with unilateral price effects. In other words, the same merger can cause the merged firm to scale back its product development efforts, due to lessened innovation competition, and also to charge higher prices for whatever products it nonetheless introduces in the future, by virtue of its unified control over more of those products. Appendix A discusses the interaction between unilateral innovation effects and unilateral price effects.

\subsection{Beneficial Effects on Innovation: Innovation Synergies}

Mergers can also promote innovation by allowing beneficial coordination between the two merging firms. Indeed, when two firms propose to merge and there are antitrust concerns related to innovation along the lines just described, the merging parties often assert that the merger will generate R\&D synergies and thus speed up innovation. In evaluating these claims, synergies that would likely be achieved without the merger are not credited. Furthermore, the burden rests on the merging parties to establish any claimed synergies. ${ }^{18}$

One category of synergies that is amenable to economic analysis is the internalization of involuntary spillovers. There is a substantial literature on technological spillovers, including involuntary knowledge spillovers between competing firms. These types of spillovers arise in situations where one firm's successful innovation is non-rivalrous and only partially excludable; see Romer (1990). For example, rivals to an innovative firm may be able to partially imitate its new product without infringing that firm's intellectual property.

In theory, the internalization of involuntary spillovers can partially or fully offset the reduced incentive to innovate resulting from the internalization of business-stealing effects, as discussed in Shapiro (2012). D’Aspremont and Jacquemin (1988) provide an early theoretical example, in which a merger can increase R\&D investment and benefit consumers if these spillovers are large. Lopez and Vives (forthcoming) present similar results, in a setting where firms are induced to cooperate by the presence of common ownership. ${ }^{19}$

This work supports the proposition that a merger can increase innovation and ultimately benefit consumers if spillovers are sufficiently high, due to higher post-merger appropriability. However, the significance of these appropriability effects in any given case may be limited. For example, the internalization of involuntary spillovers would not be merger-specific, and thus not credited, if it can be achieved through a research joint venture (RJV). A RJV would be less anticompetitive than a full merger, as it would preserve price competition in the current and future product market. In addition, the U.S. Horizontal Merger Guidelines state: “Cognizable efficiencies are merger-specific efficiencies that have been verified and do not arise from anticompetitive reductions in output or service.” This statement could be read to rule out the

\footnotetext{
18 The U.S. Horizontal Merger Guidelines, Section 10, "Efficiencies," states that "it is incumbent upon the merging firms to substantiate efficiency claims so that the Agencies can verify by reasonable means the likelihood and magnitude of each asserted efficiency, how and when each would be achieved (and any costs of doing so), how each would enhance the merged firm's ability and incentive to compete, and why each would be merger-specific.”

${ }^{19}$ In the case of sequential price competition between differentiated products (the most policy-relevant case that they consider), Lopez and Vives find the following: for low spillovers, symmetric cooperation reduces R\&D spending and increases prices; for intermediate spillovers it increases R\&D spending and prices; and for high spillovers it increases R\&D spending and lowers prices. These ranges are illustrated using numerical examples in their sequential Constant Elasticity Bertrand model.
} 
argument that a merger can be beneficial because it will diminish pricing competition and thereby allow the merged entity to appropriate a greater portion of the value of newly developed products. $^{20}$

A second category of innovation synergies arises if the merger facilitates voluntary technology transfer between the merging firms. When merging firms claim synergies of this type, the burden rests upon them to establish that the beneficial technology transfer would not have taken place without the merger, e.g., an through an ex ante RJV or an ex post licensing agreement. ${ }^{21}$ One common example in this type of synergy arises if a merger would increase the scale over which a particular process innovation may be deployed. In that case, the burden is on the merging firms to establish that they could not achieve the same benefits ex ante by jointly developing the process innovation, and that they could not realize the gains from trade ex post by having the non-innovating firm license the process innovation to lower its production costs or as a result of the innovating firm gaining customers from the non-innovating firm. Simply asserting that the innovating firm would not license to its rivals is insufficient in this situation, with apparent ex post gains from trade at a mutually acceptable running royalty rate.

A third category of innovation synergies arises if combining the two firms' development teams will enable them to be more efficient in developing new products. The U.S. Horizontal Merger Guidelines state: "When evaluating the effects of a merger on innovation, the Agencies consider the ability of the merged firm to conduct research or development more effectively." The effects of such R\&D synergies are similar to those associated with a merger's enablement of voluntary knowledge sharing. Both effects rely (at least in part) on asset complementarities between the merging firms, and both can boost the incentives to engage in costly R\&D, yielding similar effects to those resulting from the internalization of involuntary spillovers. ${ }^{22}$

The significance of such R\&D synergies in any given merger depends heavily on how R\&D is conducted at the two merging firms and whether these firms have complementary capabilities.

\footnotetext{
${ }^{20}$ If monopoly is to be preferred to competition for this reason, despite the obvious danger to consumers, an exemption to the antitrust laws would arguably need to be established. A similar issue has arisen in the context of the American Express litigation (see Katz and Sallet (2018) and their discussion of the legal principles set out by the U.S. Supreme Court in National Society of Professional Engineers (1978); and the discussion of price and non-price competition in Carlton and Winter (2018)). Appendix A discusses the relationship between unilateral price effects and innovation incentives by reference to formal economic models.

${ }^{21}$ Motta and Tarantino (2018) model a RJV that enables two firms to capture economies of scale in R\&D investment without having to engage in a full merger. They show in a simultaneous pricing and investment game that the RJV is superior to a merger in terms of both R\&D investment and consumer welfare.

${ }^{22}$ Recent formal models of mergers and innovation consider the impact of R\&D synergies on innovation incentives and consumer welfare. Motta and Tarantino (2018) model the case where a merger to monopoly leads to lower R\&D costs. Their results are qualitatively similar to those of Lopez and Vives (forthcoming), discussed above. Federico et al. (2018) find comparable results in a sequential model of stochastic product innovation followed by price competition. They model a situation in which a merger between rival innovators boosts the effectiveness of their innovation efforts (this can be thought as a proxy for the impact of the enablement of voluntary knowledge spillovers a result of the merger). In their simulations, there is an intermediate level for the increase in innovation effectiveness at which the innovation effort by each of the merging firms remains at the pre-merger level (just offsetting the negative impact of the internalization of innovation diversion). There is a higher level for the postmerger increase in the effectiveness of innovation which offsets the negative effect of the merger on overall consumer welfare (hence also mitigating the adverse impact of the merger on price competition for both existing and innovative products).
} 
R\&D synergies of this type are a special case of the much broader category of synergies arising from the combination of complementary assets within a single firm. In principle, a merger can reduce the incremental costs of $R \& D$ as a result of economies of scale and scope captured by the merged entity, and/or by bringing together complementary R\&D capabilities. ${ }^{23}$ A merger that leads to lower incremental $R \& D$ costs would naturally increase the incentives to carry out $R \& D$ and may hence lead to greater innovation. Evaluating a merger for this type of synergy tends to be a highly fact-specific inquiry.

In practice it is quite important to distinguish post-merger reductions in the incremental cost of $R \& D$ from cost saving resulting from the elimination of $R \& D$ projects in the same area. This is the familiar distinction between a shift or tilt in the cost curve and a movement along the cost curve. The latter are not efficiencies that can benefit consumers. To the contrary, evidence of a planned post-merger reduction of so-called "duplicative” R\&D projects provides a direct indication that a merger may lead to an anti-competitive suppression of innovation efforts. ${ }^{24}$ In this context, reference to "duplicative” R\&D programs may simply be a euphemism for the existence of “competing” R\&D projects, just as merging firms eliminate “duplicative” products or retail stores. The elimination of innovation competition between rival innovators following a merger may naturally result in the suppression of such competing R\&D programs.

Together with the analysis of R\&D synergies, in practice one also must consider the realistic danger that a merger will cause $\mathrm{R} \& \mathrm{D}$ dis-synergies. In some cases, $\mathrm{R} \& \mathrm{D}$ dis-synergies arise because highly skilled personnel depart from the merged entity; this can occur for a variety of reasons. More fundamentally, $\mathrm{R} \& \mathrm{D}$ dis-synergies can arise because the merged entity is organizationally incapable of proceeding ahead with multiple approaches to developing a new product or to solving some business problem. This danger is well understood in the literature on business strategy. Dis-synergies of this type can be significant and should not be neglected in merger analysis. ${ }^{25}$ Put differently, competition among multiple organizations may make possible a greater diversity of approaches than a single organization can realistically support.

Ultimately, the merging parties must show that any claimed innovation synergies are (1) likely to result from the merger, (2) would not be achieved through an alternative arrangement that preserves more competition, and (3) are material, and hence capable in principle of offsetting not only the reduction in innovation incentives caused by the merger, but also the harm to current and future product market competition and to customers brought about by unilateral price effects (net of any efficiencies in production cost).

\footnotetext{
${ }^{23}$ Incremental R\&D costs refer to costs that vary at the margin with the level of R\&D effort. A reduction in incremental R\&D costs implies a reduction in the total cost of R\&D for any given level of R\&D effort (that, the R\&D cost curve shifts downwards and/or becomes flatter).

${ }^{24}$ This concern is explicitly noted in the U.S. Horizontal Merger Guidelines: "Research and development cost savings may be substantial and yet not be cognizable efficiencies because they are difficult to verify or result from anticompetitive reductions in innovative activities.” They are also implicitly noted in the European Commission Horizontal Merger Guidelines (paragraph 80).

${ }^{25}$ Similar ideas relating to the value of organizational diversity can be found in Sah and Stiglitz (1987), and in Bresnahan et al. (2012). Rubinfeld and Hoven (2001) discuss of the benefits of competition for diversity in R\&D, with a specific application to merger enforcement in the U.S. defense sector. For formal models of competition and R\&D diversity see Letina (2016) and Gilbert (2019b).
} 


\subsection{The Misleading Economic Literature on "Competition and Innovation"}

Despite the compelling economic logic associated with the internalization of business-stealing effects, which provides a clear procedure for analyzing innovation effects in horizontal mergers, a narrative has developed, based on a number of papers on the topic of "competition and innovation," that antitrust enforcers should be tolerant of horizontal mergers when innovation is involved because "too much competition might be bad for innovation." This narrative is summarized with reference to a purported inverted U-shaped relationship between "competition" and "innovation." ${ }^{26}$ As one might expect, the narrative that "too much competition might be bad for innovation" has become popular among firms seeking to merge. ${ }^{27}$ However, that conclusion does not follow from a more careful reading of the literature.

To see why, consider an industry in a zero-expected-profit, free-entry equilibrium with significant markups over marginal cost, in which the dynamic process of entry and competition is unimpeded. Suppose that innovation is an important dimension of competition in this industry. Innovation will be carried out at some equilibrium level, driven by firms’ R\&D investments. In this setting, one type of question an economist can ask is how the equilibrium level of innovation will vary with market characteristics, such as the size of the market or the extent to which consumers value variety. This is often the question posed in the literature by asking, for example, if innovation would be higher or lower if the products in the model were more differentiated. However, comparative-static questions of this type are not directly relevant for merger control policy, and this literature has been misinterpreted and misused in practice.

In this paper, we focus instead on economic questions that are informative regarding competition policy. For that purpose, one holds the market characteristics constant, including the demand structure, product characteristics and the firms' cost functions, and seeks to predict what happens to innovation when competition is lessened because of a merger or by exclusionary conduct. Absent synergies, a merger between significant rival innovators is likely to cause innovation to decline, for the reasons provided above. The misleading narrative that "too much competition might be bad for innovation" fundamentally confuses and conflates two very different economic questions: (1) the impact on innovation when the underlying demand or cost conditions in an industry change, and (2) the impact on innovation of a proposed merger between two rival firms, taken as given the underlying conditions in the industry.

Shapiro (2012) addresses in detail the proposition that "too much competition might be bad for innovation.” He highlights the considerable empirical evidence that greater competition meaning that future sales are more contestable - spurs innovation. He also points out that the models used in this literature generally do not analyze the effects of mergers, but instead look at exogenous variations in the intensity of product market competition. ${ }^{28}$ Indeed, the authors of the cited papers often do not assert that their analysis applies to the antitrust analysis of mergers.

\footnotetext{
${ }^{26}$ See, especially, Aghion et al. (2005) and Aghion and Griffith (2005).

${ }^{27}$ For example, this argument has been used by industry associations in the context of consolidation in the European mobile telephony sector (see BCG/ETNO, "Reforming Europe's Telecoms Regulation to Enable the Digital Single Market” (2013) and Frontier Economics/GSMA, “European Mobile Network Operators Mergers” (2014)).

${ }^{28}$ Models in this literature typically consider variations in the intensity of product market competition, but do not take into account the impact of coordination in R\&D activities (which a merger would bring about). This approach can provide at best a partial view of the impact of a merger on R\&D incentives. This literature also models changes
} 


\section{Horizontal Mergers and Innovation: Applications and Case Studies}

We now turn to the application of these ideas in practice, including a discussion of some important specific cases in the United States and in Europe. We divide our analysis into three parts, reflecting three distinct fact patterns that emerge in practice.

First, we consider mergers involving competing firms with identifiable products or projects in the development pipeline. This category includes "product to pipeline” overlaps, where one merging firm has an existing product and the other is developing a competing product. Cases of this type typically implicate relatively short-run innovation competition. This category also includes "pipeline to pipeline" overlaps, where each firm is developing a new product and those products will compete against each other if and when they both are introduced. Cases of this type typically implicate medium-run innovation competition. Second, we consider mergers involving established firms with competing innovation capabilities. This cases implicate longer-run innovation competition. These two types of cases are not mutually exclusive; for example, a merger can easily involve identifiable competing pipeline products as well as overlapping capabilities that raise longer-term concerns about possible harm to innovation.

Third, we consider situations in which a large firm with a dominant position seeks to acquire a smaller firm with innovative capabilities that may (but may not) ripen into a threat. These cases can involve disruptive entrants, although future product overlaps may be hard to discern.

We focus on unilateral innovation effects, but these effects typically arise together with unilateral price effects on future products. In practice, analyzing unilateral price effects for future products can be more challenging than analyzing unilateral price effects for existing products, for two reasons: (1) there is normally some uncertainty about whether and when those future products will actually be introduced, and just what their attributes will be if they are introduced, and (2) it is typically very difficult to measure substitution patterns for future products, simply due to the paucity of available data. The lack of data does not indicate the absence of an antitrust issue.

More generally, as we embark on applications and look at case studies, it is important to note that analyzing the effect of a proposed merger on innovation is necessarily a predictive exercise involving a considerable amount of uncertainty. Indeed, merging firms often argue that any concerns about harm to innovation are speculative, because the process of developing new products is uncertain, because market conditions in the future are hard to predict, and because competition can arise from unexpected sources. These points may well be valid to some degree, but they do not provide a sound basis for dismissing the harm to innovation that is inherent when business-stealing effects are internalized. Indeed, one might just as well take the opposite view:

in product market competition by relying on proxies that do not explicitly capture the impact of a merger between two rival firms. For example, these papers often look at changes in market-wide parameters such as the degree of product differentiation, the strength of the constraint from a competitive fringe, or the price elasticity of industry demand. These exogenous changes in the intensity of product market competition are not good proxies for the impact of a merger. Some models in this literature also look at the impact on innovation of exogenous variations in the number of firms and corresponding products; see Vives (2008), and more recently Gilbert et al. (2018), and Marshall and Parra (2018)). This approach also does not capture the impact of a merger, since a merger allows for the coordination of decisions on R\&D efforts and on price by two firms, without implying that the assets and products of one of the two firms simply disappear. Papers in this literature also usually do not take into account the impact on consumer welfare resulting from the loss of product variety due to the (assumed) disappearance of a given firm/product. Recent formal models of mergers and innovation in oligopoly settings (e.g. Igami and Uetake (2019); Motta and Tarantino (2018); and Federico et al. (2018)) do not support the theoretical predictions of an inverted-U. 
that mergers combining innovation rivals are more worrisome than mergers that only combine rival products, because innovation is such a powerful contributor to consumer surplus and economic growth. Furthermore, claims by the merging parties that their merger will generate innovation synergies are also likely to involve a great deal of uncertainty, and possibly hubris.

In practice, addressing the defense that innovation effects from mergers are "speculative” raises the issue of whether one focuses more on the general economic principles described above, or instead on specific products or development projects, where the quantum of available evidence varies from case to case and can be quite limited. In practice, one rarely has real-world evidence on how two products that are not yet launched will compete against each other or what their respective sales will be. At best, one has projections, and even those are rarely available until product launch is imminent, in part because each firm typically has limited insight into the status of development efforts at other firms, making it difficult for the firms to study and predict how their products will compete. For all of these reasons, the more difficult it is to discern the specifics of future competition, the wiser it may be to rely on the general economic principles described above. Requiring the government to offer precise quantitative evidence of future competition to meet its burden of proof regarding unilateral innovation effects would be tantamount to giving up on merger enforcement relating to the development of future products that are early in the development stage or not yet discovered. ${ }^{29}$

\subsection{Product-to-Pipeline and Pipeline-to-Pipeline Overlaps}

These types of overlaps arise if one or both of the merging firms owns a specific project that is being developed or considered but has not yet reached the market. A leading example of a pipeline product is a pharmaceutical drug (or molecule) that has been discovered but is still in the development pipeline. Drug development can take many years and require very large investments to conduct scientific tests related to medical efficacy and possible side effects.

In some sectors, notably the pharmaceutical sector, and the agro-chemical sector, the development pipeline is a well-structured process driven by regulatory requirements. These development pipelines can span many years and involve a number of well-defined steps, such as Phase I, Phase II and Phase III testing in pharmaceutical development. In other sectors, the development of pipeline products is not driven by regulatory requirements, and hence is less structured. For example, a pipeline activity may simply correspond the decision by a firm to open a production facility in a new geographic market, or to enter a market with a new product with distinct attributes. In these cases, the existence of a potential new product may be less visible to competitors, but it can still be central to the antitrust analysis. Further uncertainty arises if the set of firms with pipeline products in a given area is hard to identify.

A distinct feature of some cases involving pipeline products is that they are associated relatively easily and directly with an existing product market, such as when the new product is the "next generation" version of existing products. Assessing the competitive effects of a proposed merger is more straightforward in such cases, although considerable uncertainty usually remains. When certain well-defined pipeline products are targeted at a set of existing products, the analytical techniques used for the assessment of existing product market competition can often be transposed to the assessment of mergers involving those pipeline products.

\footnotetext{
${ }^{29}$ For a related discussion see Section 2 in Kwoka (2018).
} 
The remaining "time-to-market" of a pipeline product is another important element in the competitive analysis. If most of the development costs associated with a pipeline product have already been incurred, and the launch of the new product would (absent the merger) be imminent, then the competitive concerns are very similar to those arising for overlaps of existing products. The difference then is a practical one: lack of real-world data on the demand for the new product. The main concern in such cases involves unilateral price effects due to the elimination of competition between the pipeline product owned by one of the merging firms and an existing product (or products) owned by the merging partner. Unilateral innovation concerns related to the discontinuation of the pipeline product often do not arise in this situation, given that most or all of the development costs have already been incurred. There certainly are circumstances where product suppression after a merger can occur, but these are the same circumstances under which a merged firm would drop a product that has already been launched. If a merger causes that to happen, customers are typically harmed due to a loss of product variety and due to weakened competitive pressure on remaining products.

Unilateral innovation effects are more likely to arise if the pipeline product is still relatively far from successful commercialization and significant development costs must still be incurred before that product will be ready for launch. In that case, the probability of successful product introduction with and without the merger is a central component of the analysis. Harm to innovation can arise because the merged firm devotes fewer resources to certain pipeline projects or because it reduces the number of pipeline projects that are funded at all.

As we turn to discuss different fact patterns that arise in practice, it is helpful to classify the basic competitive concerns related to pipeline products that arise in cases of this type. First, the merger may lower the probability of successful product introduction of the pipeline product. This reduction in innovation harms customers by reducing product variety and in turn applying less competitive pressure on other products in the future. Second, the merger may delay the launch of the pipeline product, which generates the same anti-competitive effects, albeit less dramatically. Third, even if the pipeline product is successfully developed despite the merger, future product market competition may be less intense because the merger has brought competing products under common ownership.

\subsubsection{Product-to-Pipeline Overlaps.}

Product-to-pipeline overlaps arise when a merger brings together a firm that owns an existing product with a rival working on a pipeline product that is a substitute for the first product. As explained in Section 2, a merger of this type internalizes business-stealing effects, because successful commercialization of the pipeline product would divert profitable sales from the existing product. A merger would thus lower the incentive to invest in the new product and to introduce it to the market, ceteris paribus. The business-stealing effect will be larger if the existing and the pipeline products are close substitutes (i.e., they address similar customer needs) and if the profit margins on the sales that would be diverted from the existing to the pipeline product are high. Both diversion and margins are more likely to be high if the existing product market is highly concentrated and if the pipeline product constitutes one of the main sources of future competition to the incumbent product.

If the pipeline development process is largely deterministic, i.e., if most uncertainty around the profitability of the pipeline product has already been resolved, then the merger may cause the merged firm to simply abandon the development efforts. Such "killer acquisitions" can be 
expected to occur if the net incremental profit from introducing the product before the merger exceeds the (remaining) development cost, but drops below that level after the merger due to the internalization of business-stealing effects. A "killer merger" can be mutually profitable for both the buyer and the seller due to the standard monopoly pre-emption effect noted by Gilbert and Newbery (1982). An incumbent incentive's to acquire a pipeline product to shut it down are greatest if the pipeline product is a strong threat to the incumbent. A credible threat that another buyer will acquire the pipeline product and invest heavily in its development can strengthen this threat. Plus, even in the other polar case where the merged firm would introduce the pipeline product without delay, consumers can still be harmed by conventional unilateral price effects.

If the pipeline development process is stochastic, and if the probability of successful development depends on the level of $\mathrm{R} \& \mathrm{D}$ investment undertaken (often a natural assumption to make), then the internalization of business-stealing effects will generally cause the merged firm to reduce its $R \& D$ efforts, which makes successful product development less likely. The expected consumer harm under this fact pattern results from the lower probability of the introduction of a new/innovative product, plus the loss of price competition between the new product and the existing product if and when the new product is successfully introduced.

Under any of these scenarios, the loss of competition from the merger depends on the strength of the business stealing effects internalized by the merger. The central object of interest is the profitability of the expected sales diverted from the existing product to the new pipeline product in the absence of the merger. This diversion effect can be assessed by considering evidence on the current and future profitability of the existing product, on the closeness between the existing product and the pipeline product, and on the duration of the expected overlap in the market between those two products. If the existing product is protected by patents, the remaining length of that patent protection is likely to be an important consideration. Significant diversion effects are more likely if the pipeline product is expected to enter the market at a time when the existing product still enjoys effective and long-lasting patent protection. ${ }^{30}$

The adverse effects for consumers deriving from the internalization of business stealing effects between the pipeline product and the existing product need to be weighed against possible procompetitive effects due to the internalization of knowledge spillovers and/or due to the existence of cognizable R\&D synergies, as discussed in Section 2.3. For example, a merger may increase the likelihood that a pipeline product is developed if it enables efficiencies in R\&D activities.

\subsubsection{Pipeline-to-Pipeline Overlaps}

Pipeline-to-pipeline overlaps arise when both merging firms own products that are still in the development pipeline. The theory of harm is similar to the one relating to product-to-pipeline overlaps. The key distinction is that the business stealing effects apply only to future products not yet on the market. This makes harder to estimate the value of diverted sales, and hence the strength of diversion effects. This is not to say that innovation concerns related to pipeline-topipeline overlaps should be of lesser importance than those associated with pipeline-to-product overlaps. To the contrary, business stealing effects due to pipeline-to-pipeline competition may be especially strong because a new and innovative product may command higher profits in the

\footnotetext{
${ }^{30}$ Cunningham et al. (2019) find evidence that probability of discontinuation of a pipeline drug is higher if there are fewer alternatives to the merged entity (suggesting that the products of the merging firms are close competitors), and if the remaining patent life on the existing product of the merged entity is longer.
} 
future than an existing product, which makes the internalization of business-stealing effects stronger. ${ }^{31}$ The difficulty with assessing harm in these cases is practical, not conceptual: it can be difficult to predict with confidence which pipeline products will be introduced, when they will be introduced, and how they will compete. The longer the time-to-market for these products, the more vexing are these practical, evidentiary concerns.

\subsubsection{Dealing with the Uncertain Nature of Product Development}

A recurring challenge in the assessment of competitive overlaps involving pipeline products is how to handle the role of uncertainty. In some industries, depending on the development phase, the average probability of successful introduction of an individual pipeline product may be relatively low (e.g. below 50\%) in the absence of the merger in question. This raises the question of how to assess competitive overlaps that are more likely not to materialize than to materialize. This issue is of central importance to the antitrust assessment of R\&D competition, given that uncertainty is a fundamental feature of $R \& D$, especially for projects that are early in the development pipeline.

Applying the consumer welfare standard under conditions of uncertainty implies that the competition agency should intervene when a merger would lead to a reduction in expected consumer welfare due to a lessening of competition. That is, the agency should compare the expected present discounted value of consumer benefits with versus without the merger. This implies that a merger can be anti-competitive even if the pipeline product has a low probability of being introduced in the absence of the merger, as long as the value to consumers of the entry by the new product is high. ${ }^{32}$

We now illustrate these points using a very simple model that incorporates uncertainty about the development of the pipeline product. Suppose that Firm A owns a pipeline project that would succeed with probability $p_{A}$ absent a merger. If the project succeeds, it would compete with an existing product owned by Firm B. Consumer surplus in that event would be $S_{A B}$. Alternatively, if Firm A's pipeline project fails, consumer surplus would be $S_{B}$, where $S_{B}<S_{A B}$ because there is less competition and less variety without Firm A's product. The expected consumer surplus without the merger is thus equal to $p_{A} S_{A B}+\left(1-p_{A}\right) S_{B}$.

How does this compare to the expected consumer surplus with the merger? The easiest case arises if the merged firm would simply kill Firm A's pipeline project due to the internalization of innovated-related business-stealing effects. In that case, expected consumer surplus with the

\footnotetext{
${ }^{31}$ In Federico et al. (2018)'s model of horizontal mergers with stochastic product innovation, the reduction in innovation incentives by each of the merging firms is larger in states where the other merging partner successfully innovates (i.e. the pipeline-to-pipeline case), relative to those states where the merging partner does not innovate (i.e. the pipeline-to-product case). That is, a merger leads to a stronger reduction in innovation incentives for each merging firm when it "catches up" with a (new) innovative product offered by the other merging firm, relative to the situation where it "escapes competition" from an (old) existing product of the other merging firm. It is worth noting that a merger reduces innovation incentives in both sets of states, so there is not an inverted-U relationship between competition and innovation; see the discussion above in Section 2.4.

32 This is the approach advocated in the report commissioned by the UK Treasury ("Unlocking digital competition, Report of the Digital Competition Expert Panel”, March 2019), under the proposed "balance of harms” approach (paragraphs 3.88-3.100). The report states in particular that that only challenging mergers where the target is more likely than not to succeed as a competitor would be "unduly cautious" (p. 13). A similar discussion can be found in Bourreau and de Streele (2019).
} 
merger is simply $S_{B}$, so the merger reduces expected consumer surplus by $p_{A}\left(S_{A B}-S_{B}\right)$. The merger deprives consumers of the chance to enjoy the benefits associated with successful product development by Firm A. Significant consumer harm can arise even if $p_{A}$ is relatively small. This occurs if the consumer benefits from successful development by Firm A, which come in the form of greater product variety and greater price competition, are substantial. Applying a "more likely than not" standard to the probability of a competitive overlap would tend to allow harmful mergers to proceed in this example, especially when the target company is working on a project that is relatively unlikely to succeed but would generate large benefits if it does. Effectively, such an approach would allow an incumbent firm to acquire a bold, risk-taking disruptive project so long as the acquisition is done early enough so the acquired project is still more likely to fail than to succeed. ${ }^{33}$ That policy would not protect competition or consumers, and it would suppress innovation and disruption. ${ }^{34}$

This same result - that a merger can harm competition and consumers even if the target pipeline product is relatively unlikely to be introduced - holds even if the merged entity would continue to pursue the target firm's pipeline project with equal vigor. In that case, the merger would not cause consumers to experience a loss of product variety, but they would still be deprived of the benefits of product market competition between Firm B's existing product and Firm A's new product.

The assessment of a merger involving uncertain pipeline products naturally becomes more complex if the merger would internalize important knowledge spillovers or lead to R\&D synergies. If the merger leads to efficiencies that are specific to the pipeline project, then these efficiencies can be incorporated into the expressions for consumer surplus set out above. For example, the merger might increase the quality of the pipeline product or make it more likely to be successfully developed. In principle, these effects could offset the loss of expected consumer welfare that would otherwise result from the merger.

In practice, antitrust enforcement agencies may not be able to measure the expected consumer surplus without the merger, or compare that with the expected consumer surplus with the merger. However, suitable evidentiary proxies can be used to identify the mergers most likely to harm consumers, by comparing the internalization of innovation-related business-stealing effects with merger-specific efficiencies. If there is uncertainty over some of the key parameters, an errorcost framework can be applied. This framework would seek to balance the expected cost of under-enforcement (e.g. the expected harm to consumers conditional on an overlap occurring

\footnotetext{
${ }^{33}$ Moreover, as we discuss below, an existing R\&D project often represents a firm's capabilities and thus may be just the most salient example of a number of possible future competitive products.

${ }^{34}$ A similar discussion is relevant in the context of patent settlements between a patent holder and a challenger, in situations of uncertainty over the validity of the patent. Courts both in the United States and in Europe have found that agreements that remove the risk of competition between the patent holder and the challenger may be anticompetitive (e.g. FTC vs Actavis Inc., 133 S. Ct. 2223, 2013; Judgement of the European General Court, Lundbeck $v$ Commission, Case T-472/13, September 2016; and Judgement of the European General Court, Servier v Commission, Case T-691/14, December 2018). These legal findings are consistent with the application of an expected consumer welfare standard, in a situation with a probabilistic counterfactual absent the agreement (due to the uncertainty over the validity of the patent). For a formal discussion of the applicability of an expected consumer welfare standard in the context of patent settlements see Shapiro (2003).
} 
without the merger) with the expected cost of over-enforcement (e.g. the expected benefit to consumers from foregone merger-specific efficiencies). ${ }^{35}$

Another consideration that may enter into the evaluation of the effects of a merger on expected consumer welfare is whether merger control policy has an effect on the ex ante profitability of undertaking costly R\&D efforts, by reducing the profitability of “entry-for-buyout." We address this point below when we discuss cases in which a large incumbent firm seeks to acquire a much smaller firm with potential disruptive capabilities.

\subsubsection{Remedies for Pipeline Overlaps}

We now turn to a discussion of how to craft appropriate structural remedies for pipeline overlaps. Many mergers in both the United States and in Europe are cleared subject to divestitures by the merging firms. Remedy design is therefore central to the overall effectiveness of merger control.

The suitable remedy for a problematic pipeline overlap depends on the nature of the broader competitive interaction between the two merging firms. If the pipeline overlap is not associated with a problematic overlap in the upstream $R \& D$ capabilities of the two firms, then a remedy that is specifically targeted at the pipeline overlap may be adequate to avoid competitive harm.

This could be the case for example if there many R\&D competitors in a specific area and yet, due to the stochastic nature of R\&D efforts, the two merging firms are two of only few firms with specific products already in the market and in the development pipeline, hence creating the possibility of a competitive overlap in a highly concentrated market, at least for a period of time. In that case, the presence of a problematic overlap between the two merging firms simply reflects the ex post realization of a stochastic $\mathrm{R} \& \mathrm{D}$ process. In this situation, a relative targeted remedy aimed at preserving competition in the area of overlap may be sufficient, because the presence of many R\&D competitors in this hypothetical scenario makes it unlikely that another such problematic overlap would soon arise in the absence of the merger. For example, in the case of a product-to-pipeline overlap, a suitable remedy may involve carving the pipeline product out from the merged entity and divesting it to a third party, together with the assets required to enable its further development and commercialization, so long as that third party then has sufficient scale and capabilities to continue developing the pipeline product and bring it to market. Alternatively, the existing product may be divested, which also would preserve competition between the existing product and the pipeline product. This targeted approach may also make sense if the merger involves a single-product competitor with a pipeline project. In this case however divesting the pipeline product would simply be equivalent to blocking the transaction.

The appropriate remedial design is significantly more complicated if the pipeline overlap created by the merger is a symptom of a broader overlap in the underlying upstream R\&D capabilities. In that case, simply divesting a product in the overlap area risks being an insufficient remedy to prevent a reduction in future competition from the merger. We return to this issue below.

\subsubsection{Case studies}

Competition agencies routinely assess the effects of mergers involving pipeline products. These cases often involve markets with well-defined development processes, where it is relatively straightforward to identify the competitive overlaps created by pipeline products. Both the U.S.

\footnotetext{
${ }^{35}$ Katz and Shelanski (2005) advocate using an error-cost framework in this context. For a discussion in the context of digital markets see also Crémer et al. (2019).
} 
and the EC agencies have reviewed several such cases involving pharmaceutical products and medical devices. Relatively recent examples in the United States include the Thoratec/Heartware merger, blocked by the FTC in 2009, and the Mallinckrodt case in 2017, where the FTC alleged that Mallinckrodt stifled competition by acquiring a drug development project that could have competed against its highly profitable existing product.

Recent cases by the EC include Medtronic/Covidien (a merger between producers of medical devices for the treatment of vascular diseases), Pfizer/Hospira (which concerned overlaps in biosimilar drugs) and Novartis/GSK (Oncology Business) (relating to overlaps across drug development phases for innovative cancer treatments). Pipeline cases need not be confined to the pharmaceutical and medical device sectors. A recent prominent example of a case involving a well-defined pipeline product in Europe was General Electric/Alstom, which concerned very large gas turbines for electricity generation. Appendix B discusses in more detail a selection of recent U.S. and EC merger cases involving pipeline products, including issues of remedy design.

\subsection{Overlaps in Capabilities}

The second broad category of mergers raising innovation concerns involves mergers between firms with competing R\&D capabilities. By this we mean mergers involving firms with a broad set of assets targeted at similar innovation areas or trajectories. These assets may include several elements required for the effective discovery, development and commercialization of new products and processes. These assets can include: intellectual property; access to technology; human capital, such as skilled scientists or engineers; R\&D facilities, such as laboratories and specialized equipment; specialized regulatory, distribution, and commercialization assets; intangible assets such as track record with customers; and access to an installed base of existing customers who can be upgraded to a new technology. These assets often make certain firms especially well-placed to discover and bring to market new and improved products.

The theory of harm in cases of this type broadly corresponds to one of the specific concerns mentioned in the U.S. Horizontal Merger Guidelines in relation to innovation and product variety. The concern is that, but for merger, the two firms with overlapping innovation capabilities would divert profitable sales from each other by coming up with new, innovative products in similar areas, and by competing in the corresponding product market. A merger between two out of a few firms with competing innovation capabilities would internalize these business-stealing effects. The merger can lead to a reduction in the incentives to initiate new R\&D efforts in the overlapping $R \& D$ areas, which would deprive consumers of some of the benefits from future product market competition in those areas. Following the general principles that we have explained in Section 2, these concerns could be offset by pro-competitive increases in appropriability due to the merger and/or by merger-specific R\&D synergies.

A merger of firms with overlapping $\mathrm{R} \& \mathrm{D}$ capabilities may naturally also involve well-defined overlaps in the development and product-market phase. For example, two agro-chemical firms with strong capabilities in a type of insecticide may have actual product and pipeline overlaps for specific insecticide products, at any point in time. Overlaps in capabilities may well go hand-inhand with observable product and pipeline overlaps, especially if the relevant capabilities are long-lived, if the development pipeline is long, and if the average commercial lifetime of products is also long. Under these conditions it is likely that the observed overlap in underlying capabilities would manifest itself in one or more product or pipeline overlaps. In principle though, given the stochastic nature of R\&D, concerns about a merger of two firms with 
overlapping innovation capabilities can arise even if those overlaps have not resulted in observable pipeline or product overlaps at the specific time when a particular merger is evaluated. This possibility needs to be assessed on a case-by-case basis.

A broad perspective is required when looking at overlaps in capabilities between merging parties, especially given the inevitable uncertainty associated with R\&D. Over time, firms with competing capabilities are likely to be involved in a portfolio of R\&D projects. The likelihood that they will "bump into each other" in the future, and hence generate business-stealing effects, can therefore be much higher than the probability that any one project will succeed.

Quantitative estimates of the magnitude of innovation diversion effects for the case of capabilities overlap are unlikely to be available in most merger reviews. However, several evidentiary proxies can be used to establish the significance of business-stealing effects arising from a merger of two firms with overlapping innovation capabilities. One natural place to look is at the importance and frequency of past product and pipeline overlaps. These may be particularly informative if innovation capabilities in the relevant overlap area are durable. Similarly, evidence on current product-to-pipeline or pipeline-to-pipeline overlaps may be a useful proxy for the overlap in the underlying R\&D capabilities. Evidence on overlapping patent portfolios may also be useful indicator of competing capabilities, especially if one can control for the quality of patents (e.g. by considering patent citations) and if one can identify the specific R\&D trajectories associated with a given patent family. Given the medium to long-term nature of possible competition concerns arising from overlaps in capabilities, evidence on the presence of significant and durable barriers to entry may be especially relevant to the competition assessment. In the light of the intrinsic difficulties of associating capabilities overlaps with a specific existing product market and predicting the nature of demand for as-yet-unknown products, the evaluation of capabilities overlap will inevitably focus on the supply-side of possible future product markets rather than on the demand side. ${ }^{36}$

The need to examine overlaps in capabilities is recognized in guidelines by competition agencies in the United States and in Europe. For example, the recently tweaked DOJ/FTC Antitrust Guidelines for the Licensing of Intellectual Property (January 2017) refer to "R\&D markets."37 These guidelines suggest that a joint venture between two firms within the same R\&D market (that is, firms with competing innovation capabilities) is unlikely to be anti-competitive if there are at least other four competitors in the relevant R\&D market. Similarly, the European Commission Horizontal Cooperation Guidelines of 2011 suggest that R\&D cooperation may affect competition in innovation and new product markets. These guidelines indicate that in the case of a well-structured innovation process, such as in the pharmaceutical industry, it may be

\footnotetext{
${ }^{36}$ See Gilbert and Sunshine (1995) and Katz and Shelanski (2005).

37 This term “R\&D markets” supersedes the earlier term, “innovation markets.” The IP Licensing Guidelines define an R\&D market as follows: "A research and development market consists of the assets comprising research and development related to the identification of a commercialize product, or directed to particular new or improved goods or processes, and the close substitutes for that research and development. When research and development is directed to particular new or improved goods or processes, the close substitutes may include research and development efforts, technologies and goods that significantly constrain the exercise of market power with respect to the relevant research and development, for example by limiting the ability and incentive of a hypothetical monopolist to reduce the pace of research and development. The Agencies will delineate a research and development market only when the capabilities to engage in the relevant research and development can be associated with specialized assets or characteristics of specific firms” (p.10-11).
} 
possible to identify competing R\&D "poles," and to assess whether there will be a sufficient number of remaining R\&D “poles" in addition to the parties to the horizontal R\&D agreement. ${ }^{38}$ This approach is analytically similar to a framework that looks at innovation capabilities to determine whether a merger between two firms with overlapping capabilities is likely to retard innovation in a specific R\&D trajectory, and more generally to diminish future competition in innovative products.

Appropriate remedy design may be particularly delicate for a merger that brings together two out of very few firms with the capability to innovate in a given area, and hence leads to an anticompetitive overlap in capabilities. As explained above, a problematic overlap in capabilities may well co-exist with (and indeed be the cause of) one or more product or pipeline overlaps. In that case, the presence of a problematic overlap may reflect a high likelihood that another such overlap will occur in the future, especially if very few firms have the necessary capabilities.

Under those circumstances, a remedy that only targets the current product and pipeline overlaps is unlikely to be sufficient to counteract the medium to long-term harm to innovation from the merger. Addressing only the current product and pipeline overlaps would provide some shortterm and medium-term relief from the harm caused by the merger, but would likely not address the longer-term harms resulting from the loss of an effective innovator in a broader area. Such a remedy would be like dealing with the visible symptoms of competition, but not with the underlying drivers. The appropriate structural remedy would instead require divesting a broader set of assets, in addition to overlapping products and pipelines, including suitable "upstream" innovation capabilities. This could include divesting the R\&D organization of one of the merging firms, its technology and IP assets, specialized human capital, access to existing customers, and so forth. However, given how delicate an R\&D organization may be, complicated "carve-outs" from an existing structure, or "mix-and-match" solutions putting together assets from both merging firms, may risk undermining the effectiveness of a structural remedy. Addressing an overlap in innovation capabilities through divestiture may therefore be significantly more complicated, and require commensurately more assets to be divested, then remedying a specific product or pipeline overlap.

The U.S. and the EC competition agencies have intervened in a number of high-profile cases involving innovative capabilities, resulting in either an abandonment of the merger, or a significant package of divestments. These cases have involved a wide variety of sectors, including rating-measurement services, stock exchanges, agro-chemicals, semi-conductor manufacturing, and oilfield services. A common theme from these cases is that they took place in sectors characterized by continuous and costly innovation, high barriers to entry, and the presence of few effective innovators. In those cases where remedies were accepted by the competition authorities, they have typically involved the divestment of significant innovation capabilities (over and above the sale of specific products or pipeline projects), aimed at replacing the loss of an independent innovator brought about by the merger. As these cases illustrate, the design of an appropriate structural remedy may be particularly challenging (if at all possible) in mergers involving rivals with significant and competing innovation capabilities. Appendix B reviews some of the more prominent recent merger cases in the United States and in the European Union involving innovation capabilities.

\footnotetext{
${ }^{38}$ See European Commission, Guidelines on the applicability of Article 101 of the Treaty on the Functioning of the European Union to horizontal cooperation agreements, January 2011, paragraphs 119-120.
} 


\subsection{Acquisitions of Potential Competitors by Dominant Firms}

The third category of mergers that we consider is the acquisition by a dominant incumbent of a firm that has a much smaller market presence but possesses the capability to innovate in a manner that could lead it to "steal" significant, profitable business from the incumbent in the future. This third category of cases is particularly relevant in the digital sector, where several large incumbent platforms, including Google, Facebook, Apple, and Microsoft, have acquired a number of smaller firms in recent years.

When a dominant firm seeks to acquire a target firm with strong capabilities that operates in an adjacent market, the analysis shares some elements with the fact patterns discussed above. One can think of the target firm as having a pipeline project - developing an enhanced version of its own core product - along with the capability to develop features that will compete against the dominant firm's product or service. However, in practice, the target firm's product is not yet a close substitute to the incumbent's product, and one is unlikely to observe prior product or pipeline overlaps to indicate the presence of overlapping capabilities. Indeed, the merging parties may argue that the merger is not horizontal at all, and the evidence on the likelihood of a future product overlap may be hazy due to inherent uncertainty.

The clearest theory of harm in the case of the acquisition of a potential competitor by a dominant incumbent is that the acquisition will eliminate a threat to the incumbent, allowing it to protect its existing rents in the market. This can be expected to harm customers both through the direct loss of an innovative product offered by the target firm and because of the reduced competitive pressure on the incumbent. In other words, this type of acquisition can harm innovation not only through the loss of a disruptive entrant but also through the knock-on effect on the incumbent's innovation incentives, since fewer of its future sales would be contestable after the merger. ${ }^{39}$

In practice, the main challenge with developing this theory of harm often is evidentiary. Given the absence of a specific pipeline overlap, it may be difficult to establish that the acquired firm is likely to "steal" business from the incumbent in the foreseeable future. Similarly, if there is a lack of evidence of past product and pipeline competition between the incumbent and the target, it may be difficult to find a suitable proxy for a capabilities overlap. This difficulty may be particularly pronounced in new and fast-moving digital markets, where it is difficult to pin down exactly which capabilities are required to be an effective innovator and competitor, and where other, non-merging firms may also credibly contest for future sales.

Facebook's 2012 acquisition of Instagram illustrates these issues nicely. ${ }^{40}$ Facebook described Instagram as a complement at the time of the merger: Facebook published text while Instagram dealt in images. ${ }^{41}$ And indeed, Facebook now uses more images than formerly. With hindsight, one can easily imagine that Instagram would have developed into a popular social media site that competed substantially and directly with Facebook. However, the uncertainty of such a prediction would have been high. At the time of the merger, classifying Instagram as a

\footnotetext{
${ }^{39}$ The indirect effect on the incumbent's innovation incentives is likely to be especially pronounced in markets characterized by significant first-mover advantages, such as can result from network effects, and in markets where competition in innovation has features similar to a patent race.

${ }^{40}$ For a more detailed discussion of this case, see Baker (2019; pp. 160-163).

${ }^{41}$ However, at least some people in Facebook internally viewed Instagram as a threat. See https://nypost.com/2019/02/26/facebook-boasted-of-buying-instagram-to-kill-the-competition-sources.
} 
threatening substitute might have been an evidentiary challenge, given its lack of track record and revenue. Now, quite a few years have passed since the merger was allowed to proceed, we will never really know how Instagram would have evolved without the merger.

Walmart's 2016 acquisition of Jet.com provides another instructive example. Jet was one of the few online retail sites that was having success competing against Amazon, and then it was snapped up by Walmart. We can observe what Walmart has done with Jet since that acquisition, but we cannot observe what Jet.com would have done without the merger. Put differently: at the time of the acquisition, was Jet primarily an online complement to Walmart's bricks and mortar operation that would allow Walmart to offer innovative retail services in competition with Amazon, or was Jet primarily a competitor to Walmart? The uncertainty over the direction of retailing was, and remains, substantial, while the standalone ability of Jet.com to compete with either Amazon or Walmart in the years ahead was similarly unknown.

Using a sliding scale can help deal with the inherent uncertainty present when deals of this type are proposed. Comparing these two examples, if Facebook's market power in social media is greater or more durable than Walmart's market power in retailing, then even a small possibility of disruption in social media is more valuable to consumers - because it will generate more innovation and more product market competition - than the same possibility in retailing.

A suitable approach in the face of uncertainty is to look at the impact of the merger on expected consumer welfare, adopting an error-cost approach (as discussed in Section 3.1.3 in relation to uncertain product development). The cost of under-enforcement will be a function of the degree and durability of the incumbent's market power, which drives the value of a loss of (future) competition from the target. If there are existing competitors to the incumbent, or potential competitors better placed than the target, then the loss of that source of potential competition may be limited. However, if there is limited "competition in the market," and the main or only locus of competition is to be found in "competition for the market," then the loss of a potential challenger can cause substantial consumer harm, increasing the cost of under-enforcement.

There are two additional useful methods for assessing acquisitions of nascent competitors. One method is to analyze the factors that determined the acquisition price to gain insight into whether the dominant incumbent is sharing monopoly rents with the target or is instead sharing the value of anticipated synergies. ${ }^{42}$ The second method is to examine previous acquisitions by the dominant incumbent to determine whether that firm has a pattern of acquiring potential rivals or, alternatively, a track record of achieving substantial synergies through similar acquisitions.

The cost of over-enforcement will depend on the presence of merger-specific efficiencies. In the case of an acquisition of a small target by a large incumbent, possible merger-specific efficiencies include synergies between the technical capabilities of the two firms, such as applying the large firm's skills and protocols to the product of the acquired firm, or an improved ability to make the two products work together. Synergies can increase the probability that the target firm's product will be successfully brought to market, or the speed with which that occurs. A dominant firm might be able to demonstrate that it successfully achieved such efficiencies in comparable prior acquisitions.

\footnotetext{
${ }^{42}$ For an illustration of this approach see the FTC's interventions in Mallinckrodt (2017), discussed in Appendix B, and CDK/Auto-Mate (2018).
} 
An important issue in these transactions is whether merger-specificity is assessed in comparison to a situation where the target remains a stand-alone competitor, or whether it is compared to acquisition by another (larger) firm whose profit streams are not threatened by the target firm. A test based on alternative transactions would be similar to the one currently adopted for "failing firms," but not otherwise applied. ${ }^{43}$ A stricter test of this type would shift the balance toward greater enforcement, even though in many cases it would be difficult for the antitrust agency to identify specific "but-for" acquisitions to use for this purpose. ${ }^{44}$

Another factor to consider when dealing with acquisitions of smaller firms by dominant incumbents is whether the prospect of being acquired provides an important ex ante incentive for smaller firms to innovate, what might be called "investment-for-buyout." While an overly strict policy of blocking all acquisitions by dominant incumbents could have some such adverse effect, a merger enforcement policy that focuses on protecting the competitive process and effectively disregards the general effects of merger enforcement on "entry-for-buyout" would promote genuine innovation, for at least three reasons. First, such a policy would discourage venture capital funders and other sources of capital from pursuing “me-too" projects designed for an anticompetitive buyout from the start, and encourage more socially beneficial innovation. ${ }^{45}$ Second, such a policy would weaken the market power of incumbents over time and thus increase the incentive to innovate in the provision of complements. Third, there is no tradeoff if the incumbent would simply shut down or reduce investment in the competing innovation after a merger, in which case none of the benefits of "investment-for-buyout" ultimately reach consumers. ${ }^{46}$ A tougher stance against anticompetitive acquisitions of smaller firms by dominant incumbents would work side-by-side with policies that protect disruptive entrants from exclusionary conduct - our very next topic - and thus promote innovation by increasing the contestability of future sales and therefore raising the expected profits from entry.

\footnotetext{
43 See Section 11 of the U.S. Horizontal Merger Guidelines, "Failure and Exiting Assets.”

${ }^{44}$ For a specific proposal on this point, see the Furman Report commissioned by the U.K. Treasury ("Unlocking digital competition, Report of the Digital Competition Expert Panel”, March 2019), p.96-97. If the proposed merger followed active rivalry to acquire the target firm, the alternative acquirer might be easier to identify. For a discussion of alternative counterfactuals in mergers (including specific cases with identifiable alternative purchasers), see Amelio et al. (2018).

${ }^{45}$ For a discussion of this point, see Cunningham et al. (2019). This paper also provides evidence that in the pharmaceutical sector mergers do not lead to the efficient redeployment of human capital from the target firm, with only $22 \%$ of pre-acquisition inventors moving to the acquirer after a merger.

${ }^{46}$ Recent formal work incorporating “investment-for-buyout” effects does not support a lenient policy towards horizontal mergers. Mermelstein et al. (forthcoming) develop a dynamic duopoly model of Cournot competition for a homogenous good which includes entry-for-buyout incentives. They find that the optimal merger control policy from a consumer welfare perspective is equivalent to a strict static policy where mergers are not allowed. One of the benefits of this policy is actually to deter inefficient investment-for-buyout. Igami and Uetake (2019) consider a dynamic oligopoly model of mergers and innovation, calibrated to the hard-disk drive industry. In their model merger control leads to a trade-off between (a) ex ante entry and survival by firms, and (b) ex post reduction in innovation and competition. Their simulations suggest that a relatively strict merger policy is desirable: in these simulations, mergers leading to fewer than six firms reduce consumer welfare, although most of the benefits arise from blocking mergers that lead to fewer than three competitors. More generally, in many standard economic models, a merger reduces innovation incentives, and yet is profitable for the merging firms (see Appendix A). Therefore, the fact that a merger allows the would-be challenger to the dominant firm to secure higher rents (compared to the but-for world) does not promote innovation. It may rather be a means for the incumbent and the challenger to share some of the rents from market power.
} 


\section{Exclusionary Conduct by Dominant Firms in Innovative Industries}

We turn now to the antitrust treatment of the business practices of dominant firms in innovative industries. We will not address the question of whether a firm is "dominant," but rather focus entirely on conduct. We focus our attention on business practices that pose a danger of retarding innovation by excluding actual or potential rivals to the dominant firm. We are especially concerned with anti-competitive business practices employed by a dominant firm in dynamic, innovative markets to exclude pesky upstarts or potential entrants - the familiar agents of disruption. Consumers can be harmed by such practices if they prevent the emergence or success of new and improved products and services, an important source of consumer surplus in markets where the dominant firm offers its products or services free of charge to consumers, as is common in digital markets.

A classic example of conduct that can be exclusionary arises when a dominant firm refuses to sell its product to customers who also purchase from its rivals. For example, some 70 years ago, the dominant local newspaper in Lorain, Ohio, facing competition from an exciting and disruptive technology - local radio broadcasting - refused to accept advertisements from those who also placed advertisements on the local radio station. The Supreme Court ruled that this conduct violated Section 2 of the Sherman Act. ${ }^{47}$

We use the term "exclusionary conduct" in a broad sense, to encompass not only conduct that blockades entry (or induces exit) by rivals, but also conduct that weakens rivals' ability to compete effectively. ${ }^{48}$ Exclusionary conduct can, for example, raise rivals' costs, reduce the quality of their products, or impede their access to important inputs or to customers.

The recent case brought by the Federal Trade Commission against Qualcomm provides an example of exclusionary conduct that can harm innovation. ${ }^{49}$ The FTC alleged that certain business practices used by Qualcomm had the effect of raising the costs of Qualcomm's rivals in the sale of modem chips, thereby reducing these rivals' incentives to invest in the R\&D necessary to develop the next generation of these modem chips. The FTC alleged that by raising rivals’ costs, Qualcomm's conduct harmed competition and fortified Qualcomm's dominant position. The FTC made this allegation notwithstanding the fact that some of Qualcomm's modem-chip rivals, notably Intel, made sizeable R\&D investments to develop new and improved modem chips. As stressed below, assessing economic effects requires a comparison of the actual outcome with a suitable but-for world reflecting the (uncertain) path that $R \& D$, investments, prices, and entry would have taken in the absence of the challenged conduct. In May 2019, the judge hearing the FTC’s case ruled that Qualcomm's conduct violated the antitrust laws.

\subsection{Establishing an Appropriate Counterfactual}

The FTC's case against Qualcomm illustrates a common feature of antitrust cases involving business practices that may harm innovation: determining empirically just how those practices

${ }^{47}$ Lorain Journal v. United States, 342 U.S. 143 (1951).

${ }^{48}$ However, we do not use the term "exclusionary conduct" to encompass competition on the merits, such as when a dominant firm offers improved products and services, even if that conduct has the effect of driving the dominant firm's rivals from the market.

${ }^{49}$ Federal Trade Commission v. Qualcomm, Case No. 17-CV-02200-LHK, United States District Court, Northern District of California. Shapiro testified on behalf of the FTC in this case. 
have affected industry evolution can be difficult, especially if a court seeks concrete evidence of what innovation would have occurred absent the anticompetitive conduct.

To see the nature of the problem, consider first the example of a company selling a branded pharmaceutical drug that makes a large payment to a generic company, which in return agrees not to offer a generic version of that drug for some period of time. In this type of "pay-for-delay" case, there typically is abundant evidence that generic entry causes drug prices to fall dramatically. Using that evidence, one can quantify the harm to customers caused by delaying generic entry. Indeed, in cases where generic entry in fact took place later, one can quite accurately estimate the harm to consumers caused by the delay of generic entry.

In sharp contrast, now consider a situation where it is alleged that a dominant incumbent has discouraged rivals from investing in $\mathrm{R} \& \mathrm{D}$, or has impeded rivals from developing or introducing new products. In that type of case, it typically is not possible to quantify the resulting harm to customers. Indeed, given the inherent uncertainties associated with the development of new products and their market reception, it is typically impossible to know what new and innovative products would have been developed, when they would have been introduced, or how popular they would have been, if not for the challenged conduct.

All of this implies that the quantum of evidence required to conclude that a dominant firm's conduct has harmed innovation and thereby violated the antitrust laws is a critical element of competition policy. A more assertive antitrust regime will find antitrust violations in cases where the challenged conduct disrupts the competitive process by impeding the incentive or ability of rivals to innovate. This is justified because economists understand that when the incentives for a certain activity (such as investing in R\&D) decline, profit maximizing firms will predictably engage in less of that activity. Thus, if one has persuasive evidence of reduced incentives to develop new products, one can reliably conclude that innovation will be lessened. A more timid antitrust policy would require evidence showing that rivals actually reduced their $R \& D$ on particular projects as a result of the challenged conduct, and that this reduction harmed customers because certain specific products were not developed. Proving those elements would be well-nigh impossible in many dynamic markets. If the evidentiary burden of proof is set too high, antitrust enforcement will be ineffective in dynamic, innovation industries.

A second major concern in these industries is a logically fallacy related to the impact of longterm technological trends. High-tech markets experience strong secular trends in cost reduction and quality improvement (where quality can be a product attribute such as speed or memory capacity). Defendants sometimes point to these market improvements (cheaper and faster products) as evidence that no exclusionary conduct has taken place. However, the correct question is whether the improvements in speed and reductions in price would have been even larger absent the exclusionary conduct. If the mere fact that an industry has experienced technological progress, with products improving and output increasing over time, were seen to be inconsistent with the presence of exclusionary conduct, that would be tantamount to significantly hindering if not abandoning antitrust enforcement in high-tech industries.

The FTC's case against Qualcomm nicely illustrates this policy tradeoff. The FTC presented evidence that Qualcomm's challenged practices enabled Qualcomm to obtain unreasonably high royalties for its standard-essential patents from smartphone manufacturers when those 
manufacturers make and sell smartphones containing non-Qualcomm modem chips. ${ }^{50}$ The FTC explained that these excessive royalties effectively raised the costs of Qualcomm's rivals and thus discouraged them from making the R\&D investments necessary to develop new and improved modem chips. That conclusion followed from the most basic economics of product development: if a firm considering investing to develop a new product expects to make fewer unit sales and to earn a smaller margin on those sales, the firm's incentive to develop that new product will inevitably be reduced. In response, Qualcomm argued that the FTC had not proven that particular suppliers of modem chips had exited the market, or pared back their R\&D, specifically because of Qualcomm's challenged practices. Requiring a government enforcement agency to provide that type of proof as a prerequisite for establishing an antitrust violation would substantially weaken antitrust enforcement in dynamic, innovative industries. ${ }^{51}$

Antitrust enforcers, economists, and the courts have long recognized that prices can decline and products improve in the presence of anticompetitive monopolization or other harmful conduct. The DOJ's 1998 monopolization case against Microsoft is one prominent example. Microsoft Windows held monopoly power in the market for operating systems used in Intel-compatible personal computers ("PCs"). ${ }^{52}$ Microsoft had introduced innovative products that improved upon prior generations of its software, including Windows 95, which offered a user interface that "enjoyed unprecedented popularity with consumers." ${ }^{53}$ However, these innovations, as valuable as they were to consumers, did not preclude harm from anticompetitive conduct. Nor were they successful as a defense to the government's claim that Microsoft had unlawfully maintained its operating system monopoly by eliminating the competitive threat posed by Netscape and Java. ${ }^{54}$

As another example, there were multiple episodes of price-fixing in dynamic and innovative high-tech markets in the 1990s and 2000s. Suppliers of liquid crystal display ("LCD”) panels (used in PC monitors and televisions) ${ }^{55}$ and dynamic random access memory ("DRAM") (used in PCs and servers) ${ }^{56}$ each admitted to illegally forming cartels aimed at fixing prices above competitive levels. High-tech markets clearly are not immune from anti-competitive practices.

\footnotetext{
${ }^{50}$ Qualcomm had made a commitment to license its standard-essential patents on reasonable terms.

${ }^{51}$ In contrast, if a private firm were seeking antitrust damages, some added causation evidence would be relevant.

52 Findings of Fact, United States v. Microsoft Corporation, Civil Actions Nos. 98-1232 and 98-1233 (United States District Court, District of Columbia, November 5, 1999), e.g. ๆף 33-34.

53 Id. ๆ 8.

${ }^{54}$ Id. e.g. 9 9 $66-68$ and 9409.

${ }^{55}$ U.S. Department of Justice, “LG, Sharp, Chunghwa Agree to Plead Guilty, Pay Total of \$585 Million in Fines for Participating in LCD Price-Fixing Conspiracies,” November 12, 2008, available at <https://www.justice.gov/ archive/opa/pr/2008/November/08-at-1002.html>; Plea Agreement, United States v. Hitachi Displays Ltd., Case No. CR 09-0247 SI (United States District Court, Northern District of California, May 26, 2009), available at $<$ https://www.justice.gov/atr/case-document/plea-agreement-163>; Morgan Bettex, “Japan Fines Sharp \$3M in LCD Price-Fixing Scheme,” Law360, December 18, 2008, available at <https://www.law360.com/articles/80800/>; European Commission, “Antitrust: Commission fines six LCD panel producers $€ 648$ million for price-fixing cartel,” IP/10/1685, December 8, 2010, available at <http://europa.eu/rapid/press-release_IP-10-1685_en.htm>.

${ }^{56}$ Non Confidential Version of the Commission Decision of 19 May 2010 relating to a proceeding under Article 101 of the Treaty on the Functioning of the European Union and Article 53 of the EEA Agreement, DRAMs, Case No. COMP/38511 (European Commission, May 19, 2010), available at <http://ec.europa.eu/competition/antitrust/ cases/dec_docs/38511/38511_1813_5.pdf>; U.S. Department of Justice, "Samsung Agrees to Plead Guilty and to
} 
Each of these products-Windows, LCDs, DRAM — is a component of PCs. Accordingly, to accept the premise that the falling price of PCs during this period serves as proof of no anticompetitive conduct in the markets for each of these components would be to defy the facts. BLS quality-adjusted price indices ${ }^{57}$ for PCs and related peripheral equipment show a rapid and unabated decline between 1990 and 2010, at an average annual rate of 20.4\%. ${ }^{58}$ During the later periods that coincided with anticompetitive behavior related to PCs (after 1995) the pace of PC price decline in fact accelerated beyond even the price drops in handsets and other high tech products. In any event, regardless of the speed of the price decline, this information is uninformative for assessing harm caused by monopolization, collusion, and other anticompetitive conduct in related input markets. This is because harm depends on what would have happened absent anticompetitive conduct in those input markets. To do this requires a suitable counterfactual for comparison. Indeed, given the ample evidence of anticompetitive conduct in the input markets for PCs, a conclusion that it had no effect on prices or qualities is unwarranted.

Precisely because it is so difficult to empirically determine the effects of specific business practices in dynamic, innovative industries, we structure our analysis by exploring antitrust rules designed to protect the competitive process. This choice offers clear advantages: it obviates the need to speculate about particular inventions in the but-for world, while taking advantage of the power of economic theory to predict the impact of the changes in incentives and abilities. In general terms, we are exploring antitrust rules that permit dominant firms to compete by offering lower prices and improved products, but prohibit them from engaging in practices that tend to exclude disruptive rivals without providing direct benefits to customers. This is the U.S. standard for an antitrust violation: preventing such behavior protects the competitive process.

We divide our analysis into two main parts: exclusion of rivals that threaten the dominant firm's position in its core market, and exclusion of rivals that seek to compete in adjacent markets. The cases against Microsoft 20 years ago illustrate these two types of fact patterns, and how the U.S. and the E.U. legal approaches have differed in some respects. The Department of Justice case against Microsoft centered on the claim that Microsoft had engaged in various practices to defend its monopoly in personal computer operating systems. The European Commission case against Microsoft was primarily based on the claim that Microsoft's was seeking to extend its monopoly power in operating systems for personal computers into adjacent markets for media players and for operating systems running on workgroup servers.

\subsection{Defense of Dominant Position}

Before discussing specific business practices, it is instructive to consider the antitrust treatment of dominant firms in innovative markets more generally. One of the most basic, underlying policy tradeoffs is nicely developed in Segal and Whinston (2007). They point out that stricter antitrust policy will increase the profits of an entrant at the expense of the incumbent. Segal and

Pay \$300 Million Criminal Fine for Role in Price Fixing Conspiracy,” October 13, 2005, available at <https://www.justice.gov/archive/atr/public/press_releases/2005/212002.htm>.

${ }^{57}$ For a description of how the U.S. Bureau of Labor Statistics and the U.S. Bureau of Economic Analysis adjust PC prices to account for changes in quality, see, for example, Bureau of Labor Statistics, "How BLS Measures Price Change for Personal Computers and Peripheral Equipment in the Consumer Price Index,” February 23, 2018, available at https://www.bls.gov/cpi/factsheets/personal-computers.htm. 
Whinston ask how shifting profits in this manner affects innovation. Their key point is that today's successful entrant can grow to be tomorrow's dominant incumbent. Indeed, in their basic model, that is inevitable, as today's entrant leapfrogs the incumbent, swapping places and becomes tomorrow's incumbent. In that model, Segal and Whinston carry out the counterfactual we describe above by altering only the ability to exclude the entrant. They show that stricter antitrust enforcement promotes innovation "precisely when it raises the incremental expected discounted profits over an innovation’s lifetime.” (p. 1707) Similarly, Gans (2012) argues that a "static" analysis can often give the right answer regarding innovation.

There are a variety of types of conduct that a dominant firm can use to exclude a rival that threatens its market power. These include tying (as in the U.S. Microsoft case), exclusive dealing, loyalty rebates, and most-favored nation ("MFN") provisions. ${ }^{59}$ In platform markets, conduct aimed at hindering multi-homing on one side of the market may be a particularly effective exclusionary strategy. Multi-homing is a strategy that encourages innovation competition because it raises contestability: consumers operating on more than one platform can more easily shift share to a more innovative product. Therefore, policies by a dominant firm that discourage multi-homing on one side of the market can have an adverse effect on innovation akin to traditional exclusive dealing arrangements. For example, imagine what would happen if Uber prohibited its drivers from driving for another platform. Since Uber is larger than Lyft, that rule would likely cause most drivers to “single home,” i.e., to drive exclusively for Uber. That would lower the number of drivers available on Lyft and might well increase wait times on Lyft, causing Lyft to be less attractive to consumers. In the short run, contestability would fall, as an innovation on the Lyft platform would be less visible to consumers, since more of them would single-home on Uber. In addition, if Lyft were to exit some geographies, Uber would feel less competitive pressure on price and on innovation in those markets.

Exclusion of a disruptive entrant inherently harms the competitive process, even if that disruptive entrant is (currently) less efficient than the dominant firm. Indeed, that pattern tends to be the norm in industries subject to significant economies of scale (e.g. due to network effects and/or learning by doing). Disrupters that are less efficient at the outset than the established dominant firm can still pose a grave competitive threat to the incumbent, because they have countervailing characteristics that appeal to consumers, or their efficiencies will improve as they gain experience and scale. Regardless of an entrant's current level of efficiency, the competitive process requires they not be squashed by conduct that does not constitute competition on the merits, which can include conduct that would not make economic sense if not for its exclusionary impact on competitors.

Some of the hardest and most important questions in this area relate to business conduct alleged to exclude nascent competitors. Because the nascent competitor's success can be highly uncertain, in order for its exclusion to have a large effect on expected consumer welfare, the value of the increased competition in the event of its success must be large. This is most likely to be the case when the incumbent has substantial and durable market power. If consumers have limited options, then even a small chance of the arrival of an effective second choice can be very

\footnotetext{
${ }^{59}$ Appendix B provides two examples of exclusionary strategies aimed at protecting market power: MFNs and loyalty rebates. An additional example of a dominant platform using MFN clauses to deter an innovative business model is the European Commission investigation of Amazon's price and non-price MFN clauses in the e-books market. See the E.C.'s Article 9 decision of May 4, 2017, and the discussion of that case in Buehler et al. (2017)).
} 
valuable to them. This observation suggests the use of a sliding scale to assess the impact of challenged business practices on competition: the greater and more durable is the incumbent's market power, the lower is the chance of success by the entrant required for that entrant to warrant protection from exclusionary conduct. This principle is essentially the same to the one we developed in connection with mergers involving uncertain pipeline products and potential challengers to a dominant firm (see Sections 3.1.3 and 3.3).

Based on the Microsoft case, jurisprudence in the United States is solid on just this point. One of the themes of the government's case was that Netscape, through Java middleware, was a threat to Microsoft's Windows monopoly. ${ }^{60}$ But that threat had not yet matured to the point of offering a direct substitute for Windows. In that critical sense, Netscape, together with the Java Virtual Machine, offered complements to Windows but only "nascent" competition for Windows. Yet in that context, the Court of Appeals concluded that this type of competition was protected under the Sherman Act and that Microsoft had violated Section 2 of the Sherman Act. ${ }^{61}$

\subsection{Extension of Dominant Position}

We turn now to the concern that a dominant firm will extend its control to adjacent markets, using the power from its dominant position to weaken or eliminate independent rivals in those markets. This type of exclusion is worrisome both as regards competition in those adjacent market and because strong rivals in adjacent markets are often the most effective actual and potential entrants into the core market.

There are a number of economic theories of harm that can support a concern about extension of market power from a primary market to an adjacent market. For example, Carlton and Waldman (2002, Section 4) show that a dominant firm can "swing” its market power to a newly emerging market by tying its primary good to a complementary product that could otherwise serve as a stepping stone for entry into the newly emerging market. Vickers (2010) discusses a number of additional theories of harm related to leveraging of intellectual property rights ("IPRs") from a primary market to secondary markets. One of these relates to the "front-loading" effect discussed above in connection to the work of Segal and Whinston (2007). Other theories apply in settings where an incumbent carries out "fundamental" innovation, with possible "follow-on" innovation undertaken by rivals. ${ }^{62}$ In such a setting, a dominant firm can have an incentive to license its fundamental innovation on terms that will discourage that follow-on innovation if successful follow-on innovators would threaten the position incumbent's position in its primary market. Indeed, this fear of displacement can cause the incumbent to simply refuse to license to followon innovators, even if they have unique assets that would hasten innovation. Related theories in this setting hinge on mechanisms connecting innovation (or entry) into an adjacent market and the incentive of a dominant firm to protect its current market power in the primary market. ${ }^{63}$ The

\footnotetext{
${ }^{60}$ See Bresnahan et al. (2012) for a review of some of the issues raised in the Microsoft case, from an organizational perspective. Shapiro (2009) discusses the failure of the remedy in the Microsoft case.

${ }^{61}$ See United States v. Microsoft Corp., 253 F.3d 34, 79 (D.C. Cir. 2001) (en banc) (per curiam) (“[I]t would be inimical to the purpose of the Sherman Act to allow monopolists free reign to squash nascent, albeit unproven, competitors at will.”). For a further discussion of the treatment of "nascent competition” in the Microsoft case see Baker (2019, chapters 8 and 10).

${ }^{62}$ For a discussion of cumulative innovation see Scotchmer (2004), Chapter 5.

${ }^{63}$ See, for example Choi and Stefanadis (2001) and Fumagalli and Motta (2018).
} 
presence of network effects in the adjacent market can render exclusionary strategies by the dominant firm particularly effective, because foreclosure can directly make rival products less attractive (see e.g. Carlton and Waldman (2002), and Katz (2018)).

Existing European jurisprudence on refusal to license IPRs covers some of the situations where a dominant firm leverages its market power to an adjacent market. This jurisprudence seeks to preserve incentives for innovation in the primary market without unduly distorting the incentives for rivals to innovate and/or to enter in adjacent markets. In practice, this means that a dominant firm faces a duty to license its IPRs to its competitors under certain "exceptional circumstances." These circumstances include the condition that access to the IPRs is indispensable to effectively compete in a secondary market, and that the refusal to license prevents the emergence of a new product for which there is consumer demand. ${ }^{64}$ U.S. antitrust law has not gone in this direction.

European law on refusal to deal was applied to the landmark abuse of dominance case against Microsoft. ${ }^{65}$ The EC's case was that Microsoft leveraged its market power in PC operating systems into the related market for operating systems for workgroup servers. The EC concluded that Microsoft did this by degrading the interoperability information provided to rival providers of operating systems for workgroup servers. As a result, Microsoft's market position in that market grew considerably over a short period of time. While the EC Decision rested legally on the application of the prevailing European jurisprudence on refusal to deal, namely IMS Health and Magill, it also contained a discussion of the incentives of Microsoft to engage in "defensive leveraging" to protect its market power in PC operating systems. ${ }^{66}$ The remedy imposed in the European Microsoft case was an obligation on Microsoft to disclose to rivals certain interoperability information on reasonable and non-discriminatory terms. ${ }^{67}$

It is noteworthy that there was no comparable case of monopoly leveraging in the United States. ${ }^{68}$ This may reflect the rather different treatment in the U.S. vs. the EU of unilateral

\footnotetext{
${ }^{64}$ For a discussion, see European Commission, Guidance on the Commission's enforcement priorities in applying Article 82 of the EC Treaty to abusive exclusionary conduct by dominant undertakings, February 2009, paragraphs 75-90.

${ }^{65}$ See European Commission, Case COMP/C-3/37.792, Microsoft, Decision of 24 March 2004. The EC decision was upheld by the European Court of First Instance in 2007 (Judgment of the Court of First Instance, 17 September 2007, Case T-201/04). The Court upheld the EC's application of the jurisprudence on refusal to deal. See Vickers (2010) for a discussion of possible economic implications from the Court's judgment in Microsoft.

${ }^{66}$ Kuhn and van Reenen (2009) argue that defensive leveraging considerations are even more relevant to the Microsoft workgroup server case than to the U.S. case, since a rival server operating system could expose an extensive set of Application Programmer Interfaces (APIs) to developers of application programs.

67 The EC found in February 2008 that Microsoft had not complied with this obligation, by charging unreasonable royalties for access to interface documentation. This decision was upheld by the General Court in Luxembourg in June 2012 (Judgment of the General Court, 27 June 2012, Case T-167/08). For a discussion of the remedies in this case, see Kuhn and van Reenen (2009).

68 The tying claims that the DOJ brought against Microsoft were dropped after the case was remanded back to the District Court by the Court of Appeals.
} 
conduct that can extend monopoly power into adjacent markets, in particular in connection to the EC requirement to provide open interfaces and equal treatment of rivals in an adjacent market. ${ }^{69}$

One common proposal to limit the extension of a dominant position is to require the dominant firm to provide non-discriminatory access to rivals in adjacent markets. The extreme case of discriminatory access arises when the dominant firm simply refuses to allow rivals to interconnect or interoperate with its dominant product. Mandating non-discriminatory access by rivals through antitrust enforcement can require addressing several thorny problems, including economic issues relating to "reasonable" access charges and technical issues relating to compatibility and the design of interfaces. These issues are particularly challenging if either the core product or the adjacent products are changing rapidly due to technological progress. Indeed, in regulated industries, notably telecommunications, specialized sector regulators, rather than competition authorities, are primarily responsible with dealing with these access issues.

The pressing issue today, especially given the intense public interest in the societal role of digital platforms, is what public policies will apply to the owner of platform that serves as the basis for a substantial ecosystem. This setting is somewhat novel: how to protect and promote competition between content or applications on a proprietary platform that may itself be competing against other platforms. An owner of such a platform could have substantial economic power if a supplier of a complementary product or service would suffer substantial harm if it were disadvantaged on the platform. Whether or not consumers are harmed depends on whether the platform owner's policies increase the overall value of the platform to users, the nature of competition among substitutes for the complement, and the ability to move away from the platform itself (which is a function of the degree of effective inter-platform competition). One difficult question in this area is the treatment of a platform that seeks to obtain more of the rents created by the platform by using tactics that reduce the share of rents that complements capture. Over time, this shift in the sharing of rents will predictably affect the returns to innovation - and therefore the amount of innovation - by both the platform and the complements. ${ }^{70}$

The DOJ and the FTC may find it particularly difficult to intervene in this type of situation, because of the hostility of the U.S. courts to imposing any duty to deal, and because of their deference to property rights. However, even after Trinko, under Aspen Ski and Kodak there can still be antitrust liability for changing a voluntarily course of dealing. Whether the current U.S. Supreme Court would uphold that theory of liability is, however, very much an open question. This could well become one of the most important antitrust issues in the coming years. If the courts interpret U.S. antitrust law in a manner that provides little or no protection for businesses operating on proprietary digital platforms, many such businesses may find themselves in a very weak position, and they may join forces with consumers to either update the U.S. antitrust laws

\footnotetext{
${ }^{69}$ The U.S. Final Judgment required Microsoft to disclose Communications Protocols used by Windows. This remedial condition related to restoring competition in the market for PC operating systems and did not reflect an independent violation by Microsoft.

${ }^{70}$ For a more detailed discussion of this point see the Stigler Center on Regulation at Chicago Booth "Committee for the Study of Digital Platforms: Market Structure and Antitrust Subcommittee Report” presented at the Digital Platforms conference May 15, 2019, available at https://research.chicagobooth.edu//media/research/stigler/pdfs/market-structure---report-as-of-15-may2019.pdf?la=en\&hash=B2F11FB118904F2AD701B78FA24F08CFF1C0F58F
} 
or impose some form of regulation on large digital platforms. ${ }^{71}$ One U.S. presidential candidate, Elizabeth Warren, has already proposed breaking up and regulating large digital platforms. ${ }^{72}$

\section{References}

Aghion, Philippe, and Peter Howitt (1992), “A model of growth through creative destruction,” Econometrica, 60, 323-351.

Aghion, Philippe, and Rachel Griffith (2005), Competition and Growth: Reconciling Theory and Evidence, Cambridge, MA: MIT Press.

Aghion, Philippe, Cristopher Harris, Peter Howitt and John Vickers (2001), “Competition, Imitation and Growth with Step-by-Step Innovation”, Review of Economic Studies, 68, 467492

Aghion, Philippe, Nick Bloom, Richard Blundell, Rachel Griffith and Peter Howitt (2005), "Competition and innovation: an inverted-U relationship", Quarterly Journal of Economics, 120(2), 701-728.

Amelio, Andrea, Thomas Buettner, Cyril Hariton, Gábor Koltay, Penelope Papandropoulos, Geza Sapi, Tommaso Valletti and Hans Zenger (2018), "Recent Developments at DG Competition: 2017/2018”, Review of Industrial Organization, 53 (4), 653-679.

Arrow, Kenneth (1962), "Economic Welfare and the Allocation of Resources to Invention.” In The Rate and Direction of Inventive Activity: Economic and Social Factors, 467-92, Princeton University Press.

Baker, Jonathan (2019), The Antitrust Paradigm, Harvard University Press.

Baker, Jonathan (2007), "Beyond Schumpeter vs. Arrow: How Antitrust Fosters Innovation”, Antitrust Law Journal, 74.

Boik, Andre and Kenneth Corts (2016), "The Effects of Platform MFNs on Competition and Entry”, Journal of Law and Economics, 59 (1), 105 - 134.

Bourreau, Marc and Bruno Jullien (2018), “Mergers, investments and demand expansion”, Economics Letters, 167, 136-141.

Bourreau, Marc, Bruno Jullien and Yassine Lefouili (2018), "Mergers, and demand-enhancing innovation”, TSE Working Paper, 18-907.

Bourreau, Marc and Alexandre de Streele (2019), "Digital conglomerates and EU Competition Policy”, Report for CERRE, March.

Bresnahan, Timothy, Shane Greenstein, and Rebecca Henderson (2012), “Schumpeterian Competition and Diseconomies of Scope: Illustrations from the Histories of Microsoft and

\footnotetext{
${ }^{71}$ See the Stigler Report (2019) for a discussion of possible regulations that could increase competition.

${ }^{72}$ Warren, Elizabeth (2019), “Here’s How We Can Break Up Big Tech.”
} 
IBM," in The Rate and Direction of Inventive Activity Revisited, Josh Lerner and Scott Stern, eds., NBER.

Crémer, Jacques, Yves-Alexandre de Montjoye and Heike Schweitzer (2019), “Competition policy for the digitial era”, Report for the European Commission.

Carlton, Dennis and Michael Waldman (2002), "The strategic use of tying to preserve and create market power in evolving industries”, RAND Journal of Economics, 33(2), 194-220.

Chen, Yongmin and Marius Schwartz (2013), "Product innovation incentives: monopoly vs. competition”, Journal of Economics \& Management Strategy, 22(3), 513-528.

Choi Jay Pil and Christodoulos Stefanadis (2001), "Tying, investment and dynamic leveraging theory”, RAND Journal of Economics, 32(1), 194-220.

Christensen, Clayton (1997), The Innovator's Dilemma.

Chugh, Randy, Nathan Goldstein, Eric Lewis, Jeffrey Lien, Deborah Minehart and Nancy Rose (2016), "Economics at the Antitrust Division 2015-2016: Household Appliances, Oil Field Services, and Airport Slots”, Review of Industrial Organization, 46, 535-556

Carlton, Dennis and Ralph Winter (2018), "Vertical most-favored-nation restraints and credit card no-surcharge rules", The Journal of Law and Economics, 61(2), 215-251.

Cunningham, Colleen, Florian Ederer, and Song Ma (2019), "Killer Acquisitions," mimeo, available at http://faculty.som.yale.edu/songma/files/cem_killeracquisitions.pdf.

d'Aspremont, Claude and Alexis Jacquemin (1988), “Cooperative and non-cooperative R\&D in duopoly with spillovers”, American Economic Review, 78(5), 1133-1137.

Denicolò, Vincenzo and Michele Polo (2018), "Duplicative research, mergers and innovation”, Economics Letters, 166, 56-59.

Farrell, Joseph and Carl Shapiro (2010), “Antitrust Evaluation of Horizontal Mergers: An Economic Alternative to Market Definition,” Berkeley Economic Journal of Theoretical Economics: Policies and Perspectives, 10.

Federico, Giulio (2017), “Horizontal mergers, innovation and the competitive process”, Journal of European Competition Law \& Practice, 8(10), 668-677.

Federico Giulio, Gregor Langus and Tommaso Valletti (2017), “A simple model of mergers and innovation”, Economics Letters, 157, 136-140.

Federico Giulio, Gregor Langus and Tommaso Valletti (2018), "Horizontal mergers and product innovation”, International Journal of Industrial Organization, 59, 1-23.

Fumagalli, Chiara and Massimo Motta (2018), "Dynamic vertical foreclosure”, mimeo.

Gans, Joshua (2011), "When is Static Analysis a Sufficient Proxy for Dynamic Considerations? Reconsidering Antitrust and Innovation", in Josh Lerner and Scott Stern (eds), Innovation Policy and the Economy, Volume 11, NBER, University of Chicago Press.

Gans, Joshua (2016), The Disruption Dilemma, MIT Press.

Gilbert, Richard (2019a), "Merger enforcement for innovation: examples and lessons for remedies," mimeo. 
Gilbert, Richard (2019b), “Competition, Mergers and R\&D Diversity”, Review of Industrial Organization, 54(3), 465-484.

Gilbert, Richard, Christian Riis and Erlend Riis (2018), "Stepwise innovation by an oligopoly”, International Journal of Industrial Organization, 61, 413-438.

Gilbert, Richard and Hillary Greene (2015), "Merging Innovation into Antitrust Agency Enforcement of the Clayton Act”, The George Washington Law Review, 83(6), 1919-1947.

Gilbert, Richard (2006), “Looking for Mr. Schumpeter: Where are we in the competitioninnovation debate?”, Chapter 6 in Adam Jaffe, Josh Lerner and Scott Stern (eds.), Innovation Policy and the Economy, Volume 6, pages 159-215

Gilbert, Richard and Steven Sunshine (1995), “Incorporating Dynamic Efficiency Concerns in Merger Analysis: The Use of Innovation Markets”, Antitrust Law Journal, 63, 569-601.

Gilbert, Richard and David Newbery (1982), "Preemptive patenting and the persistence of monopoly", American Economic Review, 72(3), 514-526.

Greenstein, Shane and Garey Ramey (1998), "Market structure, innovation and vertical product differentiation”, International Journal of Industrial Organization, 16, 285-311.

Haucap, Justus, Alexander Rasch and Joel Stiebale (2019), "How mergers affect innovation: theory and evidence”, International Journal of Industrial Organization, 63, 283-325.

Hill, Nicholas, Nancy Rose, and Tor Winston (2015), "Economics at the Antitrust Division 2014-2015: Comcast/Time Warner Cable and Applied Materials/ Tokyo Electron”, Review of Industrial Organization, 47, 425-435.

Hovenkamp, Herbert and Carl Shapiro (2018), "Horizontal Mergers, Market Structure, and Burdens of Proof”, The Yale Law Journal, 127(7), 1996-2025.

Igami, Mitsuru and Kosuke Uetake (2019), “Mergers, Innovation, and Entry-Exit Dynamics: Consolidation of the Hard Disk Drive Industry, 1996-2016”, mimeo.

Jullien, Bruno and Yassine Lefouili (2018), “Horizontal mergers and innovation”, Journal of Competition Law and Economics, 14 (3), 364-392.

Katz, Michael (2018), "Exclusionary conduct in multi-sided markets”, in OECD, Rethinking Antitrust Tools for Multi-Sided Platforms.

Katz, Michael and Jonathan Sallet (2018), "Multisided Platforms and Antitrust Enforcement”, The Yale Law Journal, 127(7), 2142 - 2175.

Katz, Michael, and Howard Shelanski (2005), “Mergers Policy and Innovation: Must Enforcement Change to Account for Technological Change?”, in Innovation Policy and the Economy, vol. 5, edited by Adam Jaffe, Josh Lerner, and Scott Stern, 109- 65. Chicago: University of Chicago Press.

Kühn, Kai-Uwe, Szabolcs Lorincz, Vincent Verouden and Annemiek Wilpshaar (2012), "Economics at DG Competition, 2011-2012”, Review of Industrial Organization, 41, 251270.

Kühn, Kai-Uwe and John van Reenen (2009), "Interoperability and market foreclosure in the European Microsoft case”, in Bruce Lyons (ed.), Cases in European Competition Policy. The Economic Analysis, 50-71.Cambridge University Press. 
Kwoka, John (2018), "Reviving Merger Control: A Comprehensive Plan for Reforming Policy and Practice,” American Antitrust Institute, available at https://www.antitrustinstitute.org/wpcontent/uploads/2018/10/Kwoka-Reviving-Merger-Control-October-2018.pdf .

Letina, Igor (2016), “The road not taken: competition and the R\&D portfolio”, RAND Journal of Economics, 47(2), 433-460.

Loertscher, Simon and Leslie Marx (forthcoming), "Merger Review for Markets with Buyer Power," Journal of Political Economy.

Lopez, Angel and Xavier Vives (forthcoming), “Overlapping Ownership, R\&D Spillovers, and Antitrust Policy”, Journal of Political Economy.

Marshall, Guillermo and Alvaro Parra (2018), “Innovation and Competition: The Role of the Product Market”, mimeo.

Mermelstein, Ben, Volker Nocke, Mark A. Satterthwaite, and Michael D. Whinston (forthcoming), "Internal versus External Growth in Industries with Scale Economies: A Computational Model of Optimal Merger Policy”, Journal of Political Economy.

Motta, Massimo and Emanuele Tarantino (2018), “The Effect of Horizontal Mergers, When Firms Compete in Prices and Investments”, mimeo.

O’Brien, Daniel and Steven Salop (2000), “Competitive effects of partial ownership: financial interest and corporate control”, Antitrust Law Journal, 67, 559-614.

Reinganum, Jennifer F. (1989), “The Timing of Innovation: Research, Development, and Diffusion”, Chapter 14 in Richard Schmalensee and Robert D. Willig (eds.), Handbook of Industrial Organization, Volume 1, 849-908.

Romer, Paul (1990), “Endogenous technical change”, Journal of Political Economy, 94, 10021037.

Rubinfeld, Daniel and John Hoven (2001), “Innovation and antitrust enforcement”, in Jerry Ellig (ed.), Dynamic competition and public policy: technology, innovation and antitrust issues, Cambridge University Press.

Sah, Raaj Kumar and Joseph Stiglitz (1987), “The Invariance of Market Innovation to the Number of Firms”, The RAND Journal of Economics, 18(1), 98-108.

Salop, Steven (2017), “An Enquiry Meet for the Case: Decision Theory, Presumptions, and Evidentiary Burdens in Formulating Antitrust Legal Standards”, mimeo.

Schumpeter, Joseph (1942), Capitalism, Socialism and Democracy, Harper.

Segal, Ilya and Michael Whinston (2007), “Antitrust in Innovative Industries”, American Economic Review, 97(5), 1703-1730.

Shapiro, Carl (2003), “Antitrust limits to patent settlements”, RAND Journal of Economics, 34(2), 391-411.

Shapiro, Carl (2010), “Merger guidelines: hedgehog to fox”, Antitrust Law Journal, 77, 701-759.

Shapiro, Carl (2012), “Competition and innovation. Did Arrow hit the bull's eye?”, chapter 7 of Josh Lerner and Scott Stern (eds.), The Rate and Direction of Inventive Activity Revisited, pages 361-404. 
Shelanski, Howard (2013), "Information, innovation, and competition policy for the internet" University of Pennsylvania Law Review, 161, 1663-1705

Stigler Center on Regulation, University of Chicago Booth School of Business, Committee for the Study of Digital Platforms, Market Structure and Antitrust Subcommittee Report, 15 May 2019, available at https://research.chicagobooth.edu/-/media/research/stigler/pdfs/marketstructure---report-as-of-15-may2019.pdf?la=en\&hash=B2F11FB118904F2AD701B78FA24F08CFF1C0F58F

Tirole, Jean (1998), The Theory of Industrial Organization, Cambridge, MA: MIT Press.

Vickers, John (2010), “Competition policy and property rights”, The Economic Journal, 120, 375-392.

Vives, Xavier (2008), “Innovation and Competitive Pressure”, Journal of Industrial Economics, 56(3), 419-469.

Werden, Gregory (1996), “A Robust Test for Consumer Welfare Enhancing Mergers Among Sellers of Differentiated Products," Journal of Industrial Economics, 44, 409-413.

Whinston, Michael (2012), “Comment” on Chapter 7 of Josh Lerner and Scott Stern (eds.), The Rate and Direction of Inventive Activity Revisited, pages 404-410. 


\section{Appendix A: The Interaction Between Unilateral Price and Innovation Effects}

A merger between rival innovators gives rise to both unilateral price effects (in relation to both existing and innovative products) and unilateral innovation effects. ${ }^{73}$ Each of these effects, taken alone, is likely to cause a lessening of current and future competition and concomitant harm to customers. The antitrust review of a merger between rival innovators will naturally seek to capture the combined impact on consumer welfare both types of effects.

We consider it significant that both unilateral price effects (the internalization of business stealing based on price cuts) and unilateral innovation effects (the internalization of business stealing based on innovation) typically diminish competition and harm consumers. ${ }^{74}$ This suggests that merger enforcement officials adopt as a simple rule the (rebuttable) economic presumption that the internalization of business-stealing effects due to a merger between two out of a limited number of innovators in a specific trajectory is likely to harm consumers through a combination of lessened innovation and higher prices.

Recent theoretical work has explored in more depth the interactions between unilateral price effects and unilateral innovation effects. The conditions under which a merger that internalizes both price and innovation diversion effects reduces expected consumer surplus have not been fully characterized as a theoretical matter. Nor has the set of conditions under which such a merger necessarily lowers innovation incentives. Some ambiguity is the norm for game-theoretic models of imperfect competition, and for models of price discrimination, so policy makers must be guided by empirical findings and by the most robust lessons from the theoretical literature. The theoretical literature can be useful as it can focus directly on how mergers affect innovation incentives, which is difficult to study empirically.

To see how unilateral price and unilateral innovation effects interact, suppose that a merger between Firm A and Firm B, by internalizing price-based diversion, enables the merged entity to profitably raise the price of Product A. In the absence of synergies, this will raise the price/cost margin on Product A and thus raise the innovation diversion ratio applicable to Product $\mathrm{B}$. This in turn implies that the merger will further reduce the incentive of the merged entity to invest in the development of improved versions of Product B. In this manner, unilateral price effects and unilateral innovation effects interact and reinforce each other, to the detriment of consumers.

On the other hand, the incentive to develop a new product is greater if the incremental profit from that product is elevated due to diminished price competition. The key theoretical question is whether we are to usefully identify circumstances under which that indirect boost to the profitability of innovation is sufficiently large that that a merger would increase net innovation

\footnotetext{
${ }^{73}$ For a policy-focused discussion see Federico (2017). For a brief discussion of the interaction between the innovation and price externalities that a merger would internalize see also Whinston (2012).

${ }^{74}$ Denicolò and Polo (2018) have recently shown that the internalization of innovation diversion effects can lead to an asymmetric R\&D outcome after a merger (where investment is re-allocated to only one of the merging firms), and actually greater overall innovation. This result is obtained in a duopoly model with perfectly homogenous products (implying that innovation by competing firms does not actually increase product variety), and perfect collusion in the product market (and hence no unilateral price effects). Whether this result could carry over to more realistic oligopoly models with differentiated products and imperfect price competition in the product market is not yet known, so it is premature to rely on this result for merger control policy. By contrast, the theoretical and empirical prediction that internalization of innovation diversion is likely to depress innovation incentives appears to be more robust, also in light of the other papers discussed in this Appendix.
} 
incentives, even after accounting for the post-merger "tax" on innovation that results from innovation diversion effects. Plus, even if this happens, under what circumstances would the merger actually benefit customers, not just the merged firm?

A more complete analysis of how unilateral price effects and unilateral innovation effects interact can become quite complex, with the results depending on the specific model used. Based on the theoretical models developed to date, we believe that the principles articulated in the main text are quite general, and that accounting for these interactions generally confirms concerns about unilateral innovation effects, so long as mergers are evaluated mergers based on their overall impact on customers.

A number of recent theoretical models have considered simple sequential oligopoly settings in which the firms first invest in innovation and then compete in price on the basis of the (observable) outcome of their innovation efforts. Sequential oligopoly models of innovation and product market competition are attractive, because the assumption that prices are set after the realization of innovative efforts is realistic, especially in the important case of competition in R\&D and stochastic product innovation. They also allow one to ask directly about the effect of a merger on customers in a model with endogenous innovation. However, it can be difficult to obtain general analytical solutions in these papers, forcing researchers to resort to numerical simulations, which as always raises the question of the appropriate parameter values.

Research results obtained in this setting suggest that unilateral price effects and unilateral innovation effects, each harmful to customers taken in isolation, are also harmful when studied together. Notably, Federico et al. (2018) considers a sequential oligopoly model of stochastic product innovation by multiple rival innovators offering differentiated products. They numerically simulate the impact of a merger between two rival innovators by looking at a number of functional forms of demand - linear, logit, and constant elasticity of substitution demand - across a range of parameters. Their simulations suggest that, in the absence of synergies, mergers generally reduce innovation incentives, increase prices, and harm customers. ${ }^{75}$

Qualitatively similar conclusions are obtained by Motta and Tarantino (2018), who perform simulations of a merger in a sequential oligopoly model of deterministic process innovation with linear demand (Shubik-Levitan) or with the Salop circular model of product differentiation. Similar results are also obtained in sequential models with a representative consumer, such as those considered by Chen and Schwarz (2013, Appendix B) ${ }^{76}$, Cunningham et al. (2019, Appendix A), and Lopez and Vives (forthcoming). ${ }^{77}$ Greenstein and Ramey (1998) also find that

\footnotetext{
${ }^{75}$ These results are shown for cases of symmetry oligopoly pre-merger, but they are generally robust to the presence of asymmetries (e.g. asymmetries in costs or in product qualities).

${ }^{76}$ Chen and Schwarz (2013) consider the incentives to innovate in a new product that competes with an existing product. The contrast the case of monopoly (where the same firm owns the old and new product), with the case of competition (where the new product can only be introduced by a firm that does not own the old product). This set-up allows for an assessment of a merger-to-monopoly, by studying change in innovation incentives between the competition and monopoly cases.

${ }^{77}$ Lopez and Vives do not model mergers directly but look instead at changes in the degree of common ownership in a market (which, in the extreme case of full common ownership, can characterize a merger-to-monopoly). They find that higher coordination between firms due to common ownership reduces R\&D investments and consumer welfare, if knowledge spillovers are low (that is, there are no countervailing innovation synergies).
} 
a duopoly setting would lead to greater innovation incentives than a (protected) monopoly in a model of vertical product differentiation à la Shaked-Sutton. ${ }^{78}$

Additional analytical results can be obtained in models with simultaneous innovation and pricing. Notably, Motta and Tarantino (2018), applying aggregative game theory, show that in a number of models with standard demand systems satisfying the Independence of Irrelevant Alternatives (e.g. the logit demand system), a merger reduces output, investment in developing new products, and consumer welfare. ${ }^{79}$ This is qualitatively in line the results from sequential models with a representative consumer. ${ }^{80}$

It is possible however to construct economic models where a merger can increase innovation incentives (even without synergies), due to the strength of unilateral price effects. Chen and Schwartz (2013) have constructed such an example. In their model of Hotelling competition, developing the new (superior) product enables a monopolist to engage in more accurate price discrimination and thus extract higher profits. ${ }^{81}$ Chen and Schwartz show by construction that this effect can be larger than the business-stealing effect that is internalized in a shift from duopoly to monopoly. However, the merger in their example still lessens competition and harms consumers, and thus would be illegal under the standards used in the United States and in the European Union. ${ }^{82}$

\footnotetext{
${ }^{78}$ Loertscher and Marx (forthcoming), consider innovation incentives in a setting with stochastic costs of production, with and without buyer power. They claim that a merger increases the per-firm innovation incentives in their benchmark case without buyer power. However, so far as we can tell, they do not incorporate cross-firm innovation diversion effects, so their characterization of the overall effects of a merger is incomplete.

${ }^{79}$ For the case of process innovation the intuition is straightforward: by reducing the output of each of the merging firms, a merger also reduces the incremental profitability of a given reduction in costs (as this is proportional to output). Motta and Tarantino (2018) shows that the same mechanism holds for product innovation, for a standard family of models where cost-reducing and quality-increasing investments are equivalent (e.g. the vertical product differentiation version of the CES and logit demand function).

${ }^{80}$ Bourreau et al. (2018) reach a similar conclusion in a simultaneous duopoly model in which firms invest in quality, for standard demand functions (e.g. CES, or models of vertical product differentiation with hedonic prices). They also consider an alternative Hotelling model of horizontal product differentiation, which a firm can invest to move its products away from rival products. In a model of that type, a merger will naturally increase the incentive to engage in such product repositioning, due to the internalization of business-stealing effects. See also the discussion in Jullien and Lefouili (2018). These results are not applicable to the canonical case in which innovation consists of product improvement and thus has predominantly a vertical dimension.

${ }^{81}$ In the Chen and Schwartz model, if a new product is introduced, then consumers that switch from the old product to the new product receive the same welfare (on aggregate), but consumers who continue purchasing the old product are harmed (due to the higher price induced by the merger). Therefore the greater innovation induced by the merger in their model is (paradoxically) harmful for consumers, as it allows the merged entity to exploit them more effectively. In other words, not only does the merger suppress future competition between the new and the existing product, but it also does not lead to any incremental consumer benefits from higher innovation, as the merged entity entirely appropriates the gains from product innovation. The monopoly case with innovation is worse (for consumers) than the monopoly case without innovation, which is in turn worse than the competitive case with innovation.

${ }^{82}$ Likewise, Bourreau and Jullien (2017) consider an alternative duopoly model of spatial differentiation and investment in coverage. In their model, absent a merger coverage is asymmetric, i.e. one of the two firms covers a larger part of the market than its competitor (but it is assumed to be constrained to set the same price in the duopoly area and in the monopoly area). In this model, a merger increases total coverage, reduces coverage in the multi-
} 
To summarize, recent theoretical work on the interaction between unilateral price effects and unilateral innovation effects supports the broad economic principle that, in the absence of efficiencies, these two effects are likely to harm consumers when considered together. In line with the general principles governing unilateral effects, the ultimate harm to consumers is likely to be larger if the merger brings together two out of a limited number of significant firms pursuing a particular innovation trajectory, in a market characterized by high barriers to entry.

\section{Appendix B: Selected Antitrust Cases Involving Innovation}

\section{B.1 Mergers Involving Pipeline Products}

\section{U.S. Cases}

The FTC regularly finds competition concerns in mergers involving pipeline products in the pharmaceutical and medical sectors.

\section{Thoratec/Heartware}

One relatively recent prominent case was the merger between Thoratec and Heartware, blocked by the FTC in 2009..$^{83}$ The merger concerned the market for left ventricular assist devices (LVADs). LVADs are a life-sustaining technology for treating end-stage heart failure patients. Thoratec was the incumbent in this market, with the only LVADs approved for commercial sale by the US Federal Drug Administration (FDA). The FTC found that Heartware was positioned to be the next company with a FDA-approved LVA, which offered novel features. Heartware was therefore a key challenger to Thoratec's market position, and was projected to capture significant market share from Thoratec after entering. The FTC also alleged that "innovation competition" between the two merging parties had already forced Thoratec to innovate its product. The FTC found that the merger would have deprived consumers from the benefits of future competition between the parties, in the form of lower prices and enhanced product features. Interestingly, the FTC was also able to rely on projections of future market share for Heartware's product to establish that the merger would have significantly increased future concentration (relative to the counterfactual without the transaction), and hence was presumptively unlawful under US law and under the US Horizontal Merger Guidelines.

\section{Mallinckrodt}

In the Mallinckrodt matter, the FTC found that a firm called Questor (currently owned by Mallinckrodt) engaged in anti-competitive monopolization (i.e. conduct contributing to the maintenance of its monopoly power). ${ }^{84}$ The conduct at stake was the disruption of the bidding process for a rival drug (Synachten), and the execution of an exclusive license to the US rights

product area, and increases prices. The net effect of the merger on consumer welfare is negative for most parameter values, based on the simulations reported by the authors.

${ }^{83}$ See FTC Complaint, Thoratec Corp. \& HeartWare Int'l, No. 9339, July 28, 2009. For a description of this case see Shelanski (2013).

${ }^{84}$ See FTC Complaint, Mallinckrodt, Civil Action No. 1:17-cv-00120, January 2017, available at: https://www.ftc.gov/system/files/documents/cases/170118mallinckrodt_complaint_public.pdf 
for the drug in 2013. This conduct eliminated the nascent competitive threat posed by an independently owned Synachten.

Questcor is the owner of Acthar, which is the only therapeutic adrenocorticotropic hormone (ACTH) product sold in the U.S., for treatment of infantile spasms, and of other indications. In its complaint the FTC presented direct evidence of substantial market power by Questor. This was illustrated by large and repeated past price increases for Achtar (in the order of $1000 \%$ or more), and by the significant profitability of the business (Mallinckrodt acquired Questor for just under USD 6 billion in 2015, with the vast majority of the value attributable to Achtar).

Synatchen is a synthetic ACTH drug, with similar biological activities and pharmacological effects as Achtar. At the time of the conduct, Synatchen was already approved and sold in several countries (e.g. in Canada and in Europe), but was not approved for commercialization by the U.S. FDA. The FTC found that Synacthen was a nascent competitive threat to Questcor's ACTH drug monopoly, notwithstanding the significant uncertainty that a preclinical drug such as Synacthen would be approved by the FDA.

In in late 2011 the owner of Syancthen decided to divest exclusive rights to seek US regulatory approval for the product, and to commercialize it. The FTC found that Questcor intervened in the bidding process for the rights at a relatively late stage (in mid-2013), and that it was ultimately successful in outbidding three alternative bidders, and in securing an exclusive license to develop, market and sell Synacthen in the US. The FTC found that Questcor's participation in the bidding process was a defensive move designed to protect its monopoly over ACTH drugs in the U.S.. By obtaining an exclusive licence to Synacthen, Questcor lessened competition by preventing another bidder from seeking to develop a competing drug, and to challenge Questcor's monopoly over ACTH drugs. ${ }^{85}$ This case is a nice illustration of the "monopoly preemption" effect, according to which a firm with significant market power may face particularly strong incentives to acquire (and to shut-down) a pipeline product that threatens its dominant market position (see discussion in the main text, Section 3.1.1). ${ }^{86}$

\section{European Commission Cases}

The European Commission has recently intervened in a number of cases involving pipeline overlaps. ${ }^{87}$ These examples often relate to mergers in pharmaceutical or medical devices, sectors that have a well-structured clinical development process.

Recent examples of intervention in pipeline-to-product overlaps include Medtronic/Covidien ${ }^{88}$, and Pfizer/Hospira ${ }^{89}$. In Medtronic/Covidien the concern related to drug-coated balloons for

\footnotetext{
85 To settle the FTC's charges, Mallinckrodt agreed to pay USD 100 million and to grant a license to develop Synacthen to a third party (together with the required assets).

${ }^{86}$ Another recent illustration of monopoly pre-emption effects is the proposed merger between CDK and Auto/Mate which the FTC challenged in March 2018. See FTC Complaint, CDK Auto/Mate, No. 9382, March 19, 2018 available at:

https://www.ftc.gov/system/files/documents/cases/docket_no_9382_cdk_automate_part_3_complaint_redacted_pub lic_version_0.pdf.

${ }^{87}$ For a review of some of these cases (including those reviewed in Section B.2), see Carles Esteva Mosso, "Innovation in EU Merger Control”, Speech at the ABA Spring Meetings, April 12, 2018.

${ }^{88}$ European Commission, Case M.7326 Medtronic/Covidien, November 282014.

${ }^{89}$ European Commission, Case M.7559 Pfizer/Hospira, August 42015.
} 
treatment of vascular diseases. Covidien had a product in late development, expected to compete with a similar existing product of Medtronic. There was only one other credible competitor in the relevant market, according to the assessment of the European Commission. The transaction would thus have resulted in a reduction from 3 to 2 independent firms, and the elimination of competition from Covidien's innovative product. The transaction was ultimately approved subject to the sale of the overlapping pipeline product.

In Pfizer/Hospira, the Commission was concerned about the overlap between an infliximab biosimilar drug of Pfizer (in Phase III testing) and the existing product of Hospira (also an infliximab biosimilar). The Commission's assessment indicated that there was only one other competitor developing a similar product. The transaction was cleared subject to the divestment of Pfizer's pipeline product.

The Commission has also found concerns in recent mergers involving pipeline-to-pipeline overlaps, including products in Phase I and Phase II of the development process.

In Novartis/GSK (Oncology Business) ${ }^{90}$, the Commission found concerns in relation to innovative cancer treatments (so-called targeted therapies). The concern related to two specific protein inhibitors (B-Raf and MEK inhibitors), for the treatment of a number of cancers. The Commission found that there were only three firms with an existing product or a product in advanced development (Phase III) for skin cancer, and also only three firms in the equivalent position for ovarian cancer. For both indications, GSK and Novartis were two out of the three competitors. The competitive concern was that the merger would have reduced Novartis's incentives to bring to develop and commercialize its own product, given that GSK's drugs were closer to the market.

Moreover, both GSK and Novartis were active in clinical research for the use of B-Raf and MEK inhibitors for the treatment of other cancers (e.g. lung cancer and colorectal cancer). The merging firms had treatment for these additional indications in earlier phases of development (Phase I and Phase II clinical trials). The parties' programs were also two of the only three competing clinical research programs based on B-Raf and MEK inhibitors. The concern was that after the merger Novartis would "rationalize” its research program, putting priority on GSK's pair of B-Raf and MEK inhibitors also for these additional treatments. Overall development efforts for the innovative targeted therapies for cancer would have suffered as a result.

The remedy in the GSK/Novartis case was to divest Novartis’ licensed MEK inhibitor to Array (the ultimate owner of the drug, which Novartis had an exclusive license for), and to divest its BRaf inhibitor to Array as well. The remedy also included transitional support to Array to enable it to complete the phase III clinical studies for the B-Raf/MEK inhibitor combination for the treatment of skin cancer. The design of the remedy was influenced by the need to keep together B-Raf and MEK inhibitors, in particular for skin cancer treatment (due to the complementarities between the two drugs).

Another example of a pipeline-to-pipeline overlap is the European Commission intervention in $J \& J /$ Actelion $^{91}$. The pipeline overlap in this case concerned products for the treatment of insomnia. Both merging parties had treatments in Phase II clinical trials. The Commission's

\footnotetext{
${ }^{90}$ European Commission, Case M.7275 Novartis/GSK (Oncology Business), January 282015.

${ }^{91}$ European Commission, Case M.8401 J\&J/Actelion, June 92017.
} 
analysis suggested that the products of the merging firms were based on a novel mechanism of action (orexin-antagonists), and that only a very limited number of other orexin-antagonists were being developed at the time. The merger therefore raised the risk of a reduction in the number of orexin-antagonist products likely to enter the insomnia market.

Pipeline concerns are not confined only to markets for pharmaceutical and medical devices. For example, the European Commission raised a specific pipeline concern in the market for HeavyDuty Gas Turbines (HDGT) in the merger between General Electric and Alstom. ${ }^{92}$ The concern arose in the market for "Very Large" gas turbines (above 320MW). At the time of the merger, General Electric had already started to commercialize its Very Large turbine, whilst Alstom had a product in late development (the GT36). The Commission's assessment was that after the merger, General Electric would have discontinued Alstom's R\&D efforts in HDGT, including halting the development and commercialization of the GT36. In this case, the Commission's innovation concerns extended beyond the GT36, and also related to Alstom's overall role as an innovator in the market. The remedy package therefore included a wide set of R\&D assets, including Alstom's technology for HDGT, existing upgrades and pipeline technology for future upgrades, a large number of Alstom R\&D engineers, and two test facilities for HDGT. This case therefore also reflects an overlap in underlying innovation capabilities (the second category of case, as we discuss below).

\section{B.2 Mergers Involving Overlapping Innovation Capabilities}

\section{U.S. Cases}

The US competition agencies have recently intervened in a number of high profile cases involving innovative capabilities. ${ }^{93}$ These cases have resulted in either an abandonment of the merger, or a package of divestments designed to replicate the loss of an independent firm with the required innovation assets.

\section{Nielsen/Arbitron}

The FTC's Nielsen/Arbitron case in 2013 was about audience measurement (rating) services. ${ }^{94}$ The FTC was concerned that the two merging parties were best placed to enter a new market for cross-platform rating services, by virtue of their strength in traditional television and radio ratings respectively. The FTC's assessment was that two companies were the only ones to operate large and demographically representative panels (including individual-level demographic data). Both parties had already initiated the development of innovative rating solutions across different platforms. The concern was that the merger would have deprived consumers from direct competition between two firms with the strongest capabilities to succeed in the future market for cross-platform rating services. In this case, the FTC did not actually allege a reduction in innovation following the merger, but simply pointed to the fact that the merger would diminish future competition in an innovative product. The transaction was cleared subject to the

\footnotetext{
${ }_{92}$ European Commission, Case M.7278 General Electric/Alstom, September 82015.

${ }^{93}$ For a more detailed discussion of some of the mergers described below, and of additional case studies, see Gilbert (2019a).

${ }^{94}$ See Statement of the Federal Trade Commission In the Matter of Nielsen Holdings N.V. and Arbitron Inc., File No. 131-0058, September 20, 2013; and FTC Press Release, “FTC puts conditions on Nielsen’s proposed \$1.26 billion acquisition of Abritron”, September 20, 2013.
} 
divestment and licensing of assets designed to replicate Arbitron's participation in cross-platform rating services.

\section{Applied Materials/ Tokyo Electron}

The Applied Materials/ Tokyo Electron deal involved two of the largest global providers of tools used to manufacture semiconductor chips. The DOJ's investigation indicated that Applied Materials (AMAT) and Tokyo Electron (TEL) were two of the most able (if not the two most able) firms with the capability to develop and manufacture leading-edge semiconductor tools for high volume manufacturing ("HVM"). The two merging parties overlapped in specific tools, including also some pipeline-to-product overlaps. But the DOJ did not stop there, as it was concerned that these overlaps could only capture an element of the broader dynamics of competition between the parties. As DOJ economists have put it in an article on this merger: "Taking a broader view, the Division found that the existing overlap between the specifically identified tools is emblematic of a broader competition to develop new deposition and etch semiconductor tools. Due to their extensive capabilities, AMAT and TEL are well positioned, if not uniquely positioned, to develop new technologies and engineer HVM tools to solve the industry's high-value deposition and etch problems" (p. 433). ${ }^{95}$ The concern was therefore squarely about overlapping innovation capabilities. Because of their unique assets, experience and track record, the merging parties were often the two best (or among the three best) development partners to address the need of a leading-edge semiconductor manufacturer. The merger would have therefore removed competition between the two parties to be chosen as a future development partner (in addition to any competition between their competing products). AMAT and TEL ultimately abandoned the merger after the DOJ found "that the proposed remedy would not have replaced the competition eliminated by the merger, particularly with respect to the development of equipment for next-generation semiconductors."96

\section{Bayer/Monsanto}

The Bayer/Monsanto merger was examined by the DOJ, and cleared subject to divestments by in 2018. ${ }^{97}$ The DOJ found that both merging firms were highly innovative, pushed each other to improve their products and technologies, and competed to develop new successful products. ${ }^{98}$ The DOJ was concerned that the merger would have suppressed current and dynamic competition in a number of areas, including genetically-modified seeds and traits in a number of important crops (cotton, soybean and canola). The DOJ was also concerned about the loss of current and future competition in some types of herbicides, and weed-management systems (the combination of a non-selective herbicide with a herbicide-tolerant seed $)^{99}$. The DOJ's complaint

\footnotetext{
95 See Hill et al. (2015).

96 See DOJ Press Release of April 27 2015, www.justice.gov/opa/pr/applied-materials-inc-and-tokyoelectron-ltdabandon-merger-plans-after-justice-department.

97 See DOJ Complaint, USA vs Bayer AG and Monsanto Company, May 292018.

${ }^{98}$ DOJ complaint, paragraph 61.

99 The DOJ was specifically concerned about the loss of innovation competition in the "bundle" of traits and herbicides, recognizing the importance of complementarities across these two areas ("Bayer is motivated to pursue trait research in part because successful commercialization of a trait will generate additional returns through the sale of the associated herbicide, and vice versa”, DOJ Competitive Impact Statement, p. 22). See also DOJ complaint, paragraph 36 ("Going forward, competition between Bayer and Monsanto to develop next-generation
} 
alleged the existence of harm to innovation (in addition to harm to price competition in a number of existing markets). ${ }^{100}$ It also identified that only two rival firms in addition to the merging companies would be able in the future to offer integrated solutions to farmers (e.g. combinations of seeds, traits and pesticides, coupled with digital farming technologies).

The remedy in this case was the divestment of a comprehensive package of assets to a third party (BASF). The assets included a number of innovation-related elements, including intellectual property, research capabilities and pipeline projects. The purpose of these elements of the divestiture was to allow BASF to obtain "all the assets required to replicate Bayer's legacy of innovation" 101 in GM seeds and traits. The package also included some of Bayer's complementary assets in herbicides, including specific pipeline projects. BASF was identified as a suitable buyer for the divestment package as it had extensive presence in agriculture, but lacked a seeds and trait business (i.e. it did not have the required R\&D capabilities, absent the remedy).

The European Commission also looked at the merger between Bayer and Monsanto. ${ }^{102}$ The concerns were similar to those found by the DOJ, and included innovation concerns in traits, herbicides and weed-management systems. The European Commission found that the merging parties were close competitors in these innovation areas, and the merger would have eliminated Bayer's as a key challenger to Monsanto's dominant position in traits and in weed management. The European Commission relied on a detailed analysis of patent data in traits, showing that the merging firms were significant and close competitors in a number of specific areas (this analysis was similar to the one developed by the European Commission in Dow/DuPont - see discussion below). Like the DOJ, the European Commission cleared the merger subject to the divestment of a significant package of assets (including R\&D capabilities) to BASF.

\section{Halliburton/Baker Hughes}

The Halliburton/Baker Hughes merger would have brought together two of the three largest global firms in oilfield services. The DOJ sued to block the merger in April 2016, and the parties subsequently abandoned the merger in May 2016. ${ }^{103}$ In its complaint against the merger, the DOJ outlined product market concerns in 23 distinct markets, but also expressed broader anticompetitive concerns resulting from the loss of dynamic competition between the two merging parties. The DOJ found that the merging firms (together with their main competitor

weed-management systems is likely to increase. According to a Bayer strategy document, the company's number one "Must Win Battle" is to "[e]stablish Liberty Link as a foundation trait for broadacre [row] crops and position Liberty herbicide as the superior weed management tool”. Liberty is the commercial name for Bayer's herbicide, and Liberty Link the name for its genetically modified seeds).

\footnotetext{
${ }^{100}$ In expressing these concerns, the DOJ specifically emphasized the role of contestability absent the merger, and of greater cannibalization after the merger ("Absent the merger, Bayer and Monsanto would have each incentives to pursue these competing pipeline projects [in next-generation weed management systems] because any new innovation developed would help win market share from the other. In contrast, the merged firm will have different incentives due to heightened concerns that new innovation would simply cannibalize sales" (DOJ Competitive Impact Statement, p.10)).

101 DOJ Competitive Impact Statement, p. 19.

102 European Commission, Case M.8084 Bayer/Monsanto, March 21 2018. For a description of the case see A. Bertuzzi et al,. "Bayer/Monsanto - protecting innovation and product competition in seeds, traits and pesticides”, Competition Merger Brief, 2/2018.

103 See DOJ Complaint, April 2016 (available at: https://www.justice.gov/atr/file/838661/download).
} 
Schlumberger) competed head-to-head in driving technological innovation and quality for the industry, in particular in complex tenders for large global clients. The evidence suggested the existence of a "persistent innovation leadership" of the top three firms in the market, supported by their global scale and scope (allowing them to capture higher returns from their investment in $\mathrm{R} \& \mathrm{D}$, to exploit synergies across product lines, and to have access to more opportunities to gain experience with new technologies). ${ }^{104}$

As a summary of its innovation concerns, the DOJ complaint stated that:

\begin{abstract}
Halliburton and Baker Hughes continue to push one another to develop the most advanced technologies for E\&P companies. Each company has engaged in competing research efforts to bring what they refer to as "game changing" or "disruptive" new technologies to market first, or to surpass each other's existing technology, in such areas as dissolvable frac plugs, drilling automation, and integrated refracturing, among others. Defendants have stated that they plan to eliminate expenditures on overlapping research projects after the proposed acquisition. The acquisition would end competition between the Halliburton and the Baker Hughes versions of key emerging technologies.

Thus, the elimination of competition between Halliburton and Baker Hughes would have more profound anticompetitive effects than market shares and HHI measures alone would indicate. These anticompetitive effects would likely include unilateral effects in the form of higher prices, lower service levels and less innovation, as well as greater coordination among the remaining competitors. (paragraphs 69-70).
\end{abstract}

The innovation concerns raised by the merger had direct implications for remedy design. The DOJ rejected the remedy package proposed by the merging parties because it did not include stand-alone business, it was a "mix-and-match" of assets from either merging firm (effectively representing a "worst-of-breed" combination of technologies), and lacked global scale in some dimensions. ${ }^{105}$ The DOJ was therefore concerned that the proposed divestment would not fully replicate the capabilities and dynamic competitive position of Baker Hughes. ${ }^{106}$

\title{
European Commission Cases
}

Like the US agencies, the European Commission too has examined several mergers of firms with rival innovation capabilities. Recent cases include Bayer/Monsanto (reviewed above in connection with the corresponding US case), General Electric/Alstom (reviewed above in connection with the specific pipeline overlap examined in that merger), Western Digital/Hitachi, Deutsche Boerse/Euronext, and Dow/DuPont (we review these cases below).

\section{Western Digital/Hitachi}

\footnotetext{
104 See Chugh et al. (2016).

105 See DOJ Complaint, paragraphs 73-69; and Chugh et al. (2016).

${ }^{106}$ In his remarks announcing the complaint against the merger, the then AAG Bill Baer put it as follows: "What Halliburton proposes to sell off or license fails to maintain today's competitive dynamic. It turns the Big Three into a Big Two, here and around the world. Halliburton mostly would keep the more successful product lines and sell assets related to the less successful product lines to some third party. But beyond that, Halliburton would withhold keep for itself - critical company-wide assets and personnel that support those product lines, because these common assets are shared with other parts of Halliburton or Baker Hughes. They are keeping the infrastructure essential to making each firm successful and just selling off some pieces. It is like selling part of a building while removing the heating system, the electrical wiring and some of the foundation” (Assistant Attorney General Bill Baer Delivers Remarks at Press Call Announcing that the Justice Department Seeks to Block Halliburton’s Acquisition of Baker Hughes, April 6, 2016).
} 
The Western Digital/Hitachi ${ }^{107}$ merger brought together two of the three leading suppliers of hard-disk drives (HDDs). This market is characterised by continuous innovation to increase the storage capacity of HDDs, and hence drive down the price per GB. Whilst the Commission did not set out a specific innovation concern in this case (and focused primarily on unilateral effects in price in the 3.5-inch desktop segment of the HDD market), innovation issues played a role in the assessment of efficiencies and in the design of the remedy. ${ }^{108}$ The European Commission did not accept the claims of cost efficiencies made by the merging forms, in part because of a concern that the merger would reduce the degree of pass-through of any future cost reduction. This is effectively an innovation concern, as it reflects the fact that a reduction in future competition will deprive consumers from the benefit of future (process) innovation. The European Commission also did not accept the claim that reduction in fixed costs would lead to greater future innovation, in the absence of a consistent economic account for why this procompetitive effect should be expected. The Western Digital/Hitachi was cleared subject to the divestment of production assets for the manufacture of 3.5-inch HDDs, including a production facility, the transfer or licensing of the IP rights, and the transfer of personnel (including R\&D personnel). The divestment was subject to an upfront clause, under which the Commission had to approve the sale of the package to a suitable buyer. This process was subject to specific purchaser criteria, aimed at ensuring that the buyer had "proven expertise and an ongoing track record as an $R \& D$ innovator within the HDD industry, and preferably proven expertise in a market neighboring a market of concern" (Commission Decision, paragraph 1086). The rationale behind this purchaser criteria was to ensure the establishment of an independent player with the required capabilities to innovate and remain competitive in the future markets for HDDs (in particular 3.5-inch HDD). The assets were eventually purchased by Toshiba (which was present in some of the related HDD markets, but not in 3.5-inch HDD).

\section{Deutsche Boerse/NYSE Euronext}

In 2012 the European Commission prohibited between the merger between Deutsche Boerse and NYSE Euronext. ${ }^{109}$ The Commission was concerned that the merger would have created a quasimonopoly in exchange-traded European financial derivatives. The Commission was specifically concerned that the merging firms were close competitors for new product introductions, and for innovations in technology, processes and market design. The analysis carried out by the Commission suggested that the competition between derivatives exchanges was characterised by "winner-takes-all" dynamics (or competition "for the market"), with each exchange seeking to come up with new contracts and ideas in order to attract and retain liquidity. ${ }^{110}$ This dynamic competitive process was found to be an important driver of the incentives to innovate. The competitive evaluation carried out by the Commission indicated that the merging parties competed at the level of introduction of new and improved contracts, and that their incentive to innovate was at least in part driven by the threat of actual or potential competition. The Commission specifically noted that even if (after the merger) a given innovation would reach the market in an equally timely fashion and in a form equally suited to customer needs, the merger

\footnotetext{
${ }^{107}$ European Commission, Case M.6203 Western Digital Ireland/Viviti Technologies, 23 November 2011.

${ }^{108}$ For a discussion of innovation issues in this case, see Kühn et al. (2012).

${ }^{109}$ European Commission, Case M. 6166 - DEUTSCHE BÖRSE / NYSE EURONEXT, Commission Decision of February 1, 2012. For a discussion of this case, see Kuhn et al. (2012).

${ }^{110}$ Commission decision, paragraph 527.
} 
would still result in less price competition during the period of establishment of the new product, and a loss of a pricing constraint from potential competition subsequently. ${ }^{111}$. The Commission also found that the competitive rivalry between Deutsche Boerse and Euronext was also present at the "upstream level”, in technology, processes and market design. The merger would have therefore weakened the incentive faced by the merging firms to innovate in technology, process and market design in order resulting in less innovation being available to customers in derivatives markets. ${ }^{112}$

The Deutsche Boerse/Euronext is notable because it was litigated in Court, following Deutsche Boerse's appeal of the Commission's decision to prohibit the merger. ${ }^{113}$ In its appeal, Deutsche Boerse claimed that the Commission's conclusion that the merging parties constrained each other through innovation competition was manifestly incorrect. The Court examined this claim by reviewing the Commission's reasoning and evidence on the loss of innovation competition between Deutsche Boerse and Euronext (in relation to both new product introduction, and competition in technology, process and market design), and dismissed Deutsche Boerse's claim in its entirety. ${ }^{114}$ The Court also dismissed the other pleas brought forward by Deutsche Boerse, and upheld the Commission's prohibition of the merger.

\section{Dow/DuPont}

The merger between Dow and DuPont brought together two of the leading global firms in crop protection. ${ }^{115}$ The Commission was concerned that the merger would have eliminated not only product market competition on existing products, but also innovation competition on future products. The innovation concerns were based on the existence of overlaps between the two merging parties in pipeline products and in discovery targets, on the importance of Dow and DuPont as innovators in specific innovation areas (as shown by the analysis of historical patent data) ${ }^{116}$, and by evidence of suppression of R\&D investment by the merged entity (based on the firms’ post-merger integration plans ${ }^{117}$ ). The Commission's innovation concerns were also based

${ }^{111}$ Commission decision, paragraphs 601-603.

112 Commission decision, paragraph 640.

113 See Judgment of the General Court, 9 March 2015, Case T 175/12.

114 See Judgement of the General Court, Case T 175/12, paragraphs 157-179.

115 See European Commission, Case M.7932 Dow/DuPont, Decision of March 27, 2017, available at http://ec.europa.eu/competition/mergers/cases/decisions/m7932_13668_3.pdf. For a description of the case see also A. Bertuzzi et al., "Dow/DuPont - protecting product and innovation competition", Competition Merger Brief, European Commission, 2/2017; and B. Buehler et al., "Recent developments at DG Competition: 2016/2017”, Review of Industrial Organization, 2017 (51), 397-422.

116 The Commission analyzed patent data for the period 2000-2015, by broad segment of crop protection (insecticides, selective herbicides and fungicides) - see in particular Annex 1 of the Commission Decision. The analysis focused on quality-adjusted patent counts, to control for the significant heterogeneity in the value of each patent. Citations were used as a measure of quality, in line with the economic literature on patenting. The analysis suggested that Dow and DuPont accounted for a significant share of high-quality patents in particular in selective herbicides and in insecticides. The data also suggested that DuPont had a much higher share of quality-adjusted patents than a simple count of its patents would suggest.

117 When announcing the deal in December 2015, Dow and DuPont presented a number of cost synergies, including synergies from elimination of “duplicative R\&D programs” in chemical discovery (see Dow and DuPont 
on the broader features of the crop protection industry, including the existence of significant barriers to entry in R\&D (e.g. as evidenced by the fact that the cost of discovery and development of a new chemical was estimated at close to USD 300m, over a 10 -year period), high market concentration (with only three additional global R\&D competitors to the merging firms), and high appropriability pre-merger (as a result of strong IPRs and effective strategies to maintain profitability of existing products after patent-expiry, resulting in high profit margins on existing products for a sustained period of time). In its decision, the Commission also addressed in some detail the implications of the economic literature for the assessment of innovation concerns in the merger (in light of the specific circumstances of the industry). ${ }^{118}$

The Dow/DuPont merger was cleared subject to the divestment of DuPont's products in the markets where the Commission established concerns (including in particular DuPont's insecticides and broadleaf herbicides), together with DuPont's global R\&D facilities in crop protection. This package was made of only DuPont assets (rather than mixing assets from both merging firms), thus preserving existing complementarities between the R\&D and lines of research and downstream product portfolios, and avoiding "worst-of-breed" concerns. The rationale for the inclusion of comprehensive $\mathrm{R} \& \mathrm{D}$ assets was both to preserve the long-term viability of the divested product portfolio, and to replicate DuPont's role as an independent competitor with significant innovation capabilities in crop protection. ${ }^{119}$

\section{B.3 Cases Involving Exclusionary Conduct that May Deter Entry and Innovation}

American Express

American Express' business model requires merchants not to discriminate against the American Express card by offering consumers a discount, coupon, or other consideration for using a different (and cheaper) card. Effectively these non-discrimination rules are an MFN that prohibits a retailer from steering business to cards that offer the retailer a better value proposition. For example, suppose an entrant wished to invest in developing a new general purpose card with a low fee. In this example the new card has a low cost strategy; it will have a very low charge to merchants so that merchants would want to use it. But because its merchant charge is low it does not collect funds to offer as rewards to consumers. Merchants would like to take this card but would be prevented by the AmEx (and now Visa/MC) non-discrimination rules from steering business to it by rewarding the customer. Instead, the customer gets rewarded with points, and therefore has an incentive to use the card with the highest possible fees. Without the ability to attract merchant business by charging a lower price, the card will expect to earn less for its innovation in a world with the MFN than without -- when it could rely on its value proposition to obtain customers. By contrast, an entering card with even richer benefits than AmEx, funded by a higher merchant charge (e.g. the Chase Sapphire card) will find entry easy because it is not trying to attract merchants, but rather end consumers. American Express's contracts were ruled legal in the United States by the Supreme Court, but many similar MFN contracts are not permitted in Europe. Competition enforcement in this environment has a direct

presentation, "DuPont and Dow to Combine in Merger of Equals Will Create Highly Focused Leading Businesses in Agriculture, Material Science and Specialty Products”, December 11, 2015).

118 See Annex 4 of the Commission decision.

119 See Commission Decision, paragraphs 4023-4044. 
impact on innovation. Allowing the MFN explicitly favors certain kinds of innovation (high cost) while disfavoring others (low cost). ${ }^{120}$

\section{Pfizer vs. Johnson and Johnson}

Innovation in the important area of biosimilars is strikingly different between the US and the EU. The US has very few biosimilars on the market, while the EU has close to 30 for sale. Biosimilars are copies of innovator biologic medicines, and hence create vigorous price competition for the innovator product, much as generic drugs do. However, biosimilars are not perfect copies and therefore cannot be substituted by the pharmacist, but instead must be prescribed by a doctor which creates a switching cost. Biosimilar regulatory approval is much more expensive than typical small-molecule generic drugs in both jurisdictions because of the complexity of biologics and the complexity of the biosimilar standard. European countries procure drugs in a much more competitive manner than the US and this is likely one reason for the rapid adoption of biosimilars and the enormous price declines European consumers have enjoyed. However, one reason for the slow entry of US biosimilars may be weak enforcement of US competition laws. ${ }^{121}$ A case filed by Pfizer (the maker of the biosimilar) against Johnson \& Johnson (the innovator Remicade) alleges that J\&J structures sales of Remicade in such a way that the biosimilar could not successfully enter the market. ${ }^{122}$ The sale contract at issue is a loyalty rebate (or fidelity discount) requiring a hospital to buy almost all of its needs in this therapeutic group (all biosimilars plus the innovator) from J\&J in order to receive a rebate on its total Remicade purchases from J\&J. "The core features of the plan are exclusionary contracts that foreclose Pfizer's access to an overwhelming share of consumers, coupled with anticompetitive bundling and coercive rebate policies designed to block both insurers from reimbursing, and hospitals and clinics from purchasing, Inflectra or other biosimilars of Remicade despite their lower pricing." 123 If the hospital does not comply by excluding Inflectra, it must pay list price for Remicade rather than receive a substantial ex post rebate. A hospital or physician is likely unwilling to switch all patients to biosimilar Inflectra if some are stable on the incumbent product. However, the biosimilar can compete with the incumbent for new patients. A loyalty rebate or exclusive contract such as the one above can leverage the "sticky" customers by choosing a threshold and discount that make it very expensive for customers to buy from the entrant. The entrant cannot attract demand (the biosimilars for Remicade have only 7\% market share together). ${ }^{124}$ Foreseeing these tactics, an entrant might rationally choose not to enter. Such exclusionary incentives are likely to lower investment and R\&D in biosimilars, a new industry where learning by doing and economies of scale are likely important, and whose performance will have effects on future healthcare costs in the US.

\footnotetext{
120 This asymmetric entry effect is explicitly modeled in Boik and Corts (2016).

121 The UK competition authority investigated the maker of Remicade in the UK for the use of loyalty rebate contracts, but ultimately did not pursue an enforcement action. https://assets.publishing.service.gov.uk/media/5c8a353bed915d5c071e1588/Remicade_No_Grounds_For_Action_d ecision_PDF_A.pdf.

122 Complaint, Pfizer Inc. v. Johnson \& Johnson, No. 2:17-cv-04180-JCJ (E.D. Pa. Sept. 20, 2017), ECF No. 1, at https://www.courtlistener.com/recap/gov.uscourts.paed.534730.1.0.pdf.

${ }^{123}$ Complaint, page 2

124 Ronny Gal, Sanford Bernstein (Feb. 26, 2019), Global Specialty Pharma \& US Biotech, "Biosimilars: adoption update in EU \& US - Dec '18 data: Herceptin \& Rituxan moving; Remicade US will not adopt in 2019.”
} 